\title{
Time to Depth Seismic Reprocessing of Vintage Data: a Case Study in the Otranto Channel (South Adriatic Sea)
}

\author{
Brancatelli G. ${ }^{1 *}$, Forlin E. ${ }^{1}$, Bertone N. ${ }^{2}$, Del Ben A. ${ }^{2}$, Geletti R. ${ }^{1}$ \\ ${ }^{1}$ National Institute of Oceanography and Applied Geophysics - OGS, Trieste, Italy \\ ${ }^{2}$ University of Trieste, Department of Mathematics and Geosciences, Trieste, Italy \\ *Corresponding author: gbrancatelli@inogs.it
}

This manuscript is a non-peer reviewed EarthArXiv PrePrint that has been submitted and accepted for publication in the book "Interpreting the subsurface seismic data", Elsevier, Eds Bell R., Iacopini D. and Vardy M. Subsequent versions of this manuscript may have different content. If accepted, the final version of this manuscript will be available via the Peer reviewed publication link on the right hand side of this website link. 


\begin{abstract}
:
In this chapter, we present a case study focused on the reprocessing of marine seismic line MS-29, acquired in 1971 in the Otranto Channel, in the South Adriatic Sea (Italy). This line crosses the channel between South Italy and Albania, a key location for understanding the geodynamics of the North Adria Plate. The work is divided into two steps. The first step consists of a modern broadband processing sequence in the time domain that allowed us to overcome low fold problems inherent in vintage data and to obtain a pre-stack time migration seismic section. The second step focused on velocity model building and pre-stack depth migration to obtain an accurate image of the subsurface. We followed a specific workflow that uses the coherence inversion technique and both layer-based and grid tomography to achieve a reliable velocity model. The reprocessing enhances the imaging of the vintage data, allowing new insight into the geological interpretation of the Otranto Channel.
\end{abstract}

Key Words: vintage data, seismic processing, depth imaging, velocity modelling, Otranto Channel 


\section{Introduction}

Among all of the geophysical techniques, seismic reflection is probably the most reliable and powerful method for subsurface exploration. Since the first active source seismic experiments, the discipline has gone through a long evolution with great advancements in both the fields of acquisition and data processing (Dragoset, 2005). It is amazing to compare seismic images of data acquired and processed 30-50 years ago with new data. Seismic exploration, usually conducted by the hydrocarbon industry, has resulted in the acquisition of enormous amounts of data all over the world. In recent years, the push in developments promoted by the hydrocarbon industry has slightly reduced, due to the environmental impact caused by the use of fossil fuels and the consequent energy transition towards renewable and sustainable sources. Nevertheless, seismic data and subsurface characterization is not only a concern of the hydrocarbon industry, but is also of interest to research activities in the fields of seismic hazards (earthquakes), geodynamics, hydrogeology (water resources), geothermal exploration, civil engineering, and oceanography, for example.

It is possible to refer to all the data acquired in the past and saved in any way until now as "legacy data". This is a wide definition, making no difference between data collected 1, 10 or 100 years ago. Therefore, we will refer to "vintage data" as seismic data that were acquired, stored and processed before 1980s-1990s with outdated technologies (Munteanu et al., 2018). Vintage data could hold significant value if properly reprocessed with today's standard techniques, which may lead to an improvement of their quality and resolution. First of all, they could help to improve the geological knowledge of an area of interest at a relatively low cost. This is a key element in the planning of new seismic acquisition, decreasing the risk of failure in imaging the targets of interest. Moreover, vintage data are sometimes located in areas lacking recent surveys or with acquisition permit restrictions due to environmental issues.

In the 1970s, the final result of seismic processing was a stacked section. Nowadays, the standard is subsurface imaging with pre-stack time (PSTM) or depth migration (PSDM). Today, data are preconditioned with modern processing sequences, which, for marine data, includes at least some of these steps: denoising, deghosting, multiple removal, Q-factor correction and deterministic or statistical designature (Sopher and Juhlin, 2013; Nicholls et al., 2015; Górszczyk et al., 2015). Seismic imaging and some of the preconditioning steps are usually designed for surveys that are characterized by high fold coverage, broadband frequency content and long acquisition spread. In this way, the chance of obtaining a high-quality subsurface image with state-of-the-art imaging methods increases. Most vintage data are affected by spatial under-sampling (low fold coverage and a sparse number of channels along the streamer) and narrow frequency bandwidth (acquisition with a conventional flat streamer towed at constant depth). Therefore, when dealing with old data, modern processing algorithms may fail. In this sense, the fundamental issue is how to apply the new processing and imaging technologies to vintage data (Nicholls et al., 2015; Górszczyk et al., 2015).

The National Institute of Oceanography and Applied Geophysics (OGS) of Italy acquired a large amount of multichannel seismic profiles in the Mediterranean Sea from 1969 until the end of the 1970s. These vintage seismic lines, totalling more than $28,000 \mathrm{~km}$, have contributed extensively to the understanding of the geology of the Mediterranean region (Finetti and Morelli, 1973; Finetti, 2005a). Following their transcription in 2002, from the original media (21-track magnetic tape) to 
3480 cartridges in SEGY format, they have continued to be a major resource for scientific research in the Mediterranean area. During this time of economic uncertainties, a modern reprocessing of vintage data is extremely useful because research funds are rarely available to acquire new scientific data. In some cases reprocessing, including PSDM, has been successfully applied (Costa et al., 2004; Geletti et al., 2014; Dal Cin et al., 2016). In other cases, modern processing techniques have failed to give satisfactory results or have not been applied. This is due to the spatial aliasing (caused by low fold data) and to the difficulties related in building reliable velocity models in presence of a low signal to noise level (Verschuur, 2013, Yilmaz, 2001, Jones, 2010).

In the case study presented in this chapter, we reprocessed the MS-29 vintage multi-channel seismic (MCS) line, acquired in 1971. The line spreads over the Otranto Channel that links the Adriatic Sea to the Ionian Sea, between Puglia (South Italy) and Albania (Figure 12.1). The MS-29 profile represents the only regional seismic profile existing in the Otranto Channel, which crosses some structures partially covered by multiple reflectors and shows different seismic facies characterizing the Adria carbonate platform and its margins.

The original data acquisition parameters ( 24 channel, $2400 \mathrm{~m}$ cable, shot spacing of $200 \mathrm{~m}$, producing a 6-fold stack with $50 \mathrm{~m}$ trace interval) created problems in the attenuation of the multiples and in imaging the geologic structures, limiting the potential for migration and seriously compromising the usefulness of the data. In this chapter, new methods are proposed to repopulate these data to allow reprocessing with modern techniques to further enhance their value. Furthermore, we adopted a specific velocity modelling workflow to achieve a reliable depth image of the investigated geological features for the first time.

Usually, in the tomographic method, the starting velocity model is obtained by the simple conversion and smoothing of root mean square (RMS) velocities through the use of the Dix's equation (Jones, 2010). However, in the presence of strong lateral velocity variations, this approach is not optimal, because the starting velocity field may not be sufficiently close to the real one, which is what the tomography method requires in order to converge (Jones, 2010). Therefore, in this study, we used the coherency inversion technique to build a velocity-depth model based on interpreted horizons and then refined it, a first time, with layer-based tomography and a second time with grid tomography. The great advantage over Dix velocity conversion is that the coherency inversion method honours the ray bending at layer boundaries, considering a non-hyperbolic common mid point (CMP) travel time (Landa et al., 1988). 


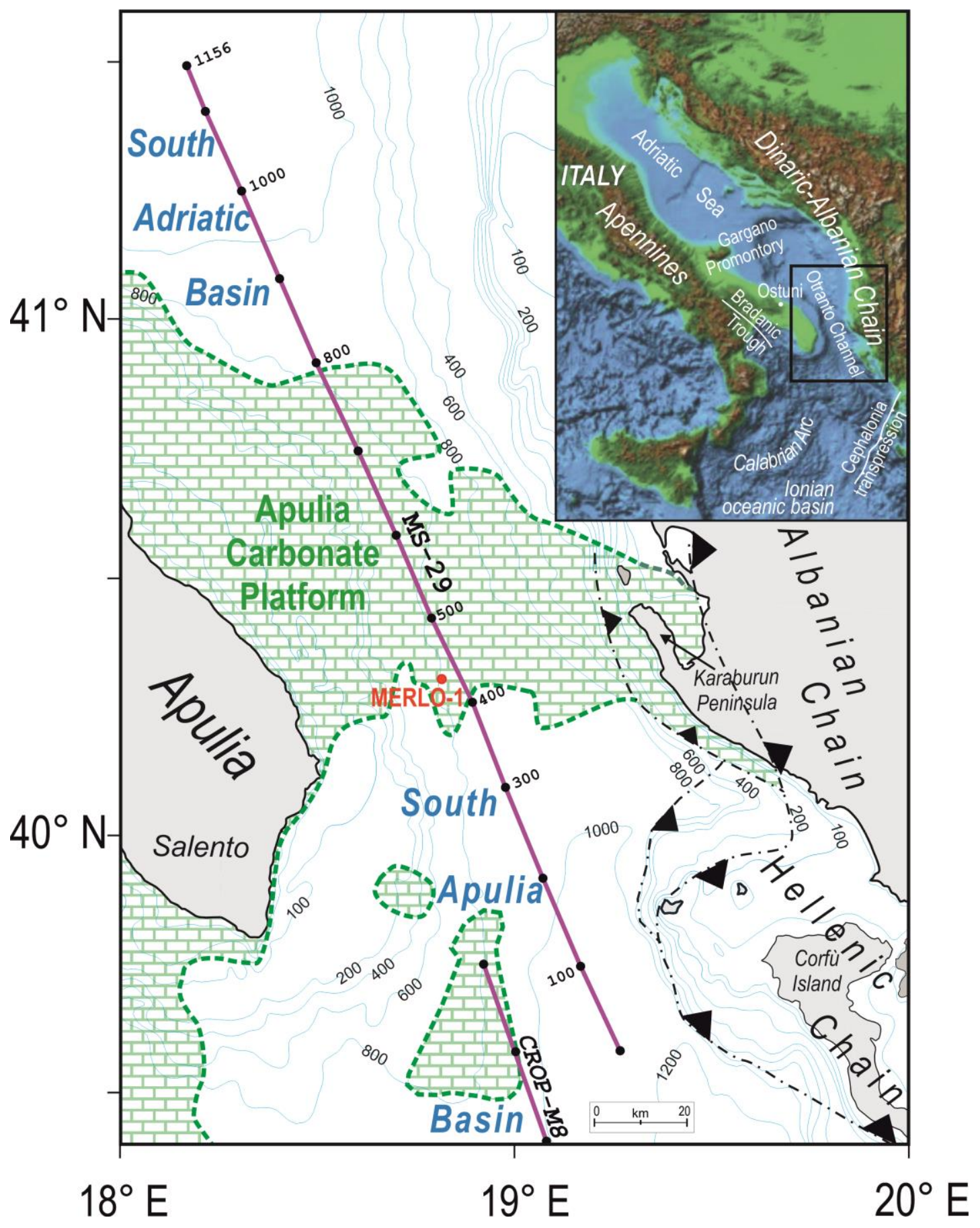

Figure 12.1: Location map showing the position of the reprocessed seismic profile MS-29 and part of the CROP-M8 profile depicted in Figure 12.22. Also shown are: bathymetric contours in thin blue lines, the Albanian/Hellenic frontal thrust in black, the margins of the Apulia carbonate platform represented by the green net (modified from Nicolai and Gambini, 2007, Mocnik, 2008, Del Ben et al., 2010, 2015). 


\section{Geological Setting}

The Apulia block was originally part of the African Plate until the Mesozoic era when, as revealed by primarily geophysical data, it was completely separated from Africa during the opening of the Neotethys (Finetti et al., 1987; Vai, 1994; Finetti et al., 2005b; Stampfli, 2005)(Figure 12.1). The Upper Triassic - Lower Jurassic period was characterized by a further phase of extension that involved the Adria as a passive continental margin, causing the formation of horst and graben structures (Mattavelli et al., 1991). During this period, a thick carbonate platform was deposited alternating with basinal sequences (Zappaterra, 1990). The passive margin persisted until the Cretaceous, when the Alpine Chain incorporated Adria in a compressive tectonic regime that continued in the Paleogene and Neogene periods.

During the Paleogene - Middle Miocene, the Dinaric Chain produced a foredeep basin filled by syn-orogenic flysch topped by the late orogenic molasse of Middle Miocene - Holocene epoch (Mattavelli et al., 1991).

From the end of the Oligocene until the Miocene, the counterclockwise rotation of the SardinianCorsican block caused the overlapping of the Apennines units on the western margin of the Adria Plate and, since the end of the Miocene until the Present, the opening of the South Tyrrhenian Sea (Finetti and Del Ben, 1986).

The Otranto Channel is located in the south Adria Plate, which represents the foreland of the Dinaric-Albanian-Hellenic and Apennines chains (Figure 12.1). The channel cuts the Apulia carbonate platform (ACP), which developed until the Cretaceous and locally until the Messinian (Bosellini et al., 2001; Del Ben et al., 2015). The Apulia carbonate platform is flanked to the northeast by the Ionian-Umbro-Marchigiano Basin and to the south-west by the Ionian-LagonegreseMolisano Basin. The carbonate platform crops out in the Apulian region, representing a relatively undeformed antiformal structure, NNW-SSE oriented, uplifted during the Pleistocene - Holocene epoch (Ricchetti et al., 1988; Cosentino and Gliozzi, 1988). It also crops out in the Gargano Promontory and in the Majella Massif. To the west of the Apulia region, the onshore Bradanic Trough is the foredeep expression of the Adria submersion below the Apennines. From the Pliocene until the Quaternary, the sedimentary succession is predominantly marly and clayey and is identified as the Santerno Formation on both the platform and the basin domains (Mattavelli et al., 1991).

The Apulia carbonate platform margin crops out in the Gargano Promontory (Bosellini et al., 1993) and along the south-eastern Salento coast (Bosellini et al., 2001). Evidence of a platform margin has also been recognized along the Salento Adriatic coast, near Ostuni (Borgomano and Philip, 1987). It continues south-east-wards into Albania, as confirmed by Argnani et al. (1996), Ballauri et al. (2002), Nicolai and Gambini (2007), Del Ben et al. (2010, 2015) (Figure 12.1).

Nicolai and Gambini (2007) also identify some intraplatform basins, mainly developed during the Late Cretaceous and, in some cases, up until the Eocene. These include the Rosaria Mare Basin, located in the Brindisi offshore region between the coastline and the platform margin to the east. The southern margin of the Apulia carbonate platform and its connection to the Pre-Apulia units are generally considered to be transitional between the platform and the Ionian/South Adriatic 
Basin. The east-ward continuation of the thick Adria carbonate platform in the Karaburun Peninsula in Albania has favoured out-of-sequence thrusting of the Ionian sequences in the Albania onshore (Ballauri et al., 2002). The first reconstruction of the southern Apulia platform margin in the EastSalento offshore region (Mocnik, 2008) delineated a complex outline around the Merlo-1 borehole and an isolated platform in the pelagic domain. The recognized margin is consistent with the outcropping of a Messinian reef, that is located along the SE-Salento shoreline (Bosellini et al., 2001). The complex boundaries of the Southern Apulia platform were also investigated by the National Hydrocarbons Agency (Ente Nazionale Idrocarburi, ENI) in the area between the Albanian coast and the Southern Salento offshore region (public report "Technical documentation on expired mining permits and concessions", Report F.R 35\&36, ViDEPI, 2009). Del Ben et al. (2015) collated all information about the Apulia carbonate platform margins and defined the boundaries of the South Apulia Basin, to the west of the Corfù Island up to the Cephalonia strike-slip fault (Figure 12.1).

This work aims at integrating information about the different facies of the Apulia carbonate platform. The reprocessed data could allow analysing the presence of the Gessoso Solfifera Formation in the study area and the connection between the Adriatic Basin and the Ionian Sea during Messinian. Moreover, the exploration of the faults system crossing the reprocessed profile could contribute to explain the seismicity present in the nearby area (Castello et al., 2006). 


\section{Data and methods}

\subsection{The Mediterranean Sea Project and the MS-29 line}

The Mediterranean Sea project (MS) was a pioneering seismic exploration project, which was conducted between 1969 and 1982 by the OGS of Trieste with the CNR's (National Research Council of Italy) ship "Marsili" (Finetti et al., 1970; Finetti and Morelli, 1972; Finetti and Morelli, 1973; Finetti et al., 2005). At the end of the project, approximately $28,000 \mathrm{~km}$ of seismic profiles were acquired across all of the Mediterranean Sea. It was the first time that the multifold seismic technique (relatively modern at that time) was applied at a regional scale in the entire Mediterranean basin for research purposes.

The acquisition equipment installed on the ship included a $2400 \mathrm{~m}$ long neutrally buoyant streamer, nominally towed at a depth of $25 \mathrm{~m}$ below sea level (b.s.l). Until 1973, the streamer connected 24 channels (each channel consisted of 20 piezoelectric ceramic hydrophones), resulting in $100 \mathrm{~m}$ trace interval. Successively, until 1982, the ship was equipped with a steamer of 48 channels, spaced every $50 \mathrm{~m}$. Data were recorded with the Digital Field System (DFS) of the Texas Instruments. The seismic source used was two or three synchronized Flexotir guns towed at $15 \mathrm{~m}$ depth, each one firing $50 \mathrm{~g}$ of Dynamite (Geodin-B). Depending upon the profile, the shot interval was set at $100 \mathrm{~m}$ or $200 \mathrm{~m}$, resulting in a fold coverage of $1200 \%$ or $600 \%$, respectively (the acquisition parameters for the MS-29 profile are listed in table 12.1). The record length of 8 to $10 \mathrm{~s}$ of two-way-time (TWT) enables (in the more favourable cases) investigations down to the deeper part of the upper crust in continental areas and enables imaging of transition to the deep oceanic basins. The data, originally stored on magnetic tapes, were recently converted and saved in a digital archive by OGS.

\begin{tabular}{|l|l|}
\hline Source & Flexotir - 3 guns $(50 \mathrm{~g} /$ gun of Dynamite, Geodin-B) \\
\hline Source depth & $15 \mathrm{~m}$ \\
\hline Streamer length & $2400 \mathrm{~m}$ \\
\hline Streamer depth & $25 \mathrm{~m}$ \\
\hline Number of channels & 24 \\
\hline Number of hydrophone/trace & 20 \\
\hline Shot interval & $200 \mathrm{~m}$ \\
\hline Near offset & $300 \mathrm{~m}$ \\
\hline Sample rate & $4 \mathrm{~ms}$ \\
\hline Record length & $8 \mathrm{~s}(\mathrm{TWT})$ \\
\hline Recording filters & Low out $10 \mathrm{~Hz} ;$ High $70 \mathrm{~Hz}$ \\
\hline
\end{tabular}

Table 12.1. Acquisition parameters for the MS-29 profile, acquired in 1971.

Many studies have been published using the MS data to understand the geodynamic and structural framework of the Central Mediterranean area (see e.g. Finetti and Morelli, 1973; D'Argenio et al., 1980; Finetti, 1982; Finetti and Del Ben, 1986). The tectonic map of the Central Mediterranean Area reported in Finetti and Del Ben (1986) still represents a valid reconstruction of the tectonokinematic setting of the area. Even now, the vintage seismic data preserve their original value but 
they could be improved with modern processing and imaging techniques. Therefore, the reprocessing of the whole MS dataset could greatly improve the geological knowledge of the Mediterranean area.

The MS-29 line was acquired between April and May 1971, in the Otranto Channel area of the South Adriatic Sea (Italy) (Figure 12.1); it has a total length of $231 \mathrm{~km}$ (1156 shot points, SP). The original processing sequence conducted in the 1970s included: gain removal, spherical divergence correction, trace editing, velocity analysis, NMO (normal move-out) correction, CDP (common depth point) gather sorting and stack, post-stack predictive deconvolution, TVF (time-variant filtering) and AGC (automatic gain control). The original stacked section (Figure 12.2) shows a low vertical resolution and a poor signal to noise level that makes it difficult to distinguish between primary signals and coherent (such as multiples) and incoherent noise.

In this chapter, we demonstrate the importance of reprocessing the MS-29 vintage data both in time and depth domain in order to obtain:

- better characterized seismic facies;

- more reliable imaging of subsurface features;

- greater capacity of detection and interpretation of fluid-related amplitude anomalies;

- improved resolution.

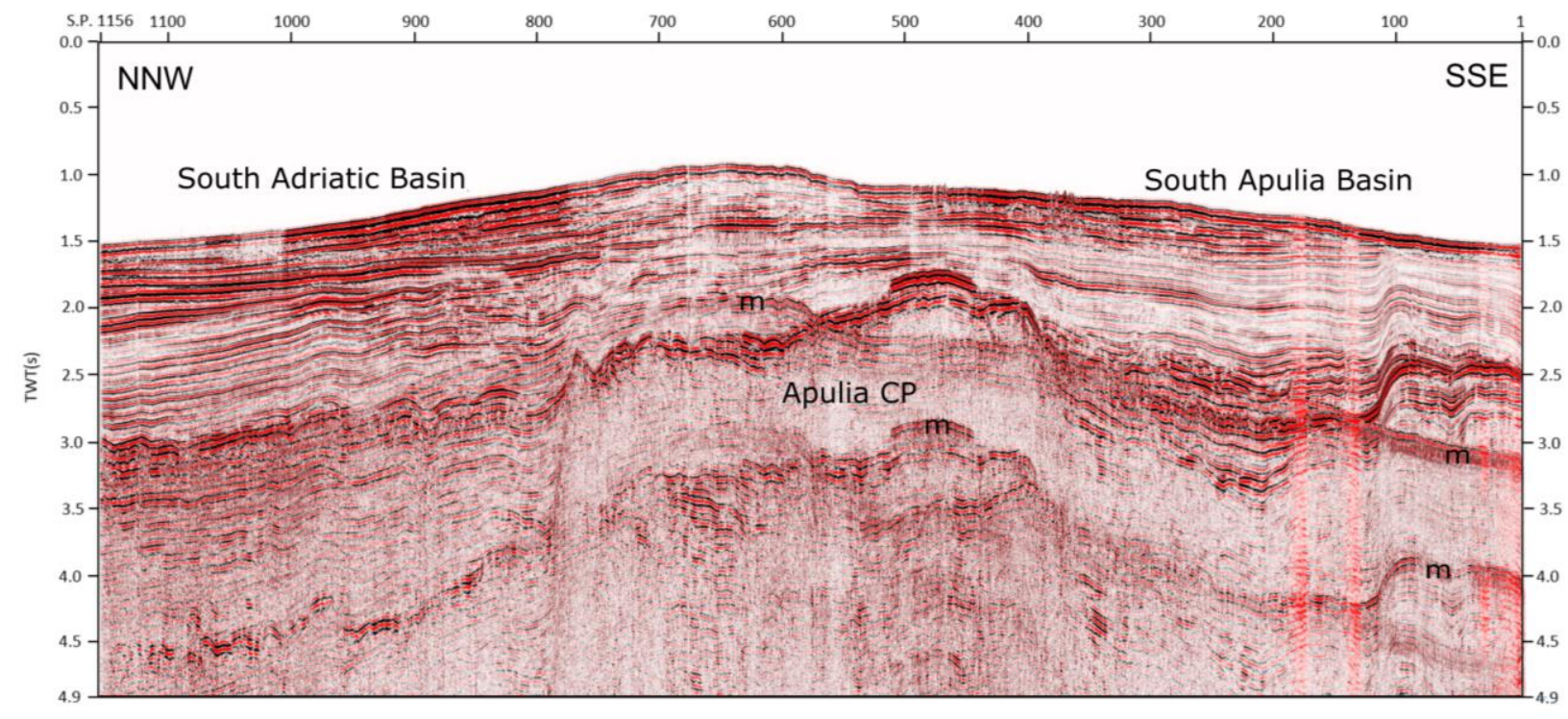

Figure 12.2: The original MS-29 stacked section, processed in the 1970s. 


\subsection{Time reprocessing}

We applied a modern broadband processing sequence to the MS-29 seismic line, culminating in PSTM (Figure 12.3). Processing and migration were performed with Emerson Paradigm - Echos and Geodepth software package. The main processing steps will be analysed and discussed in detail in this section.

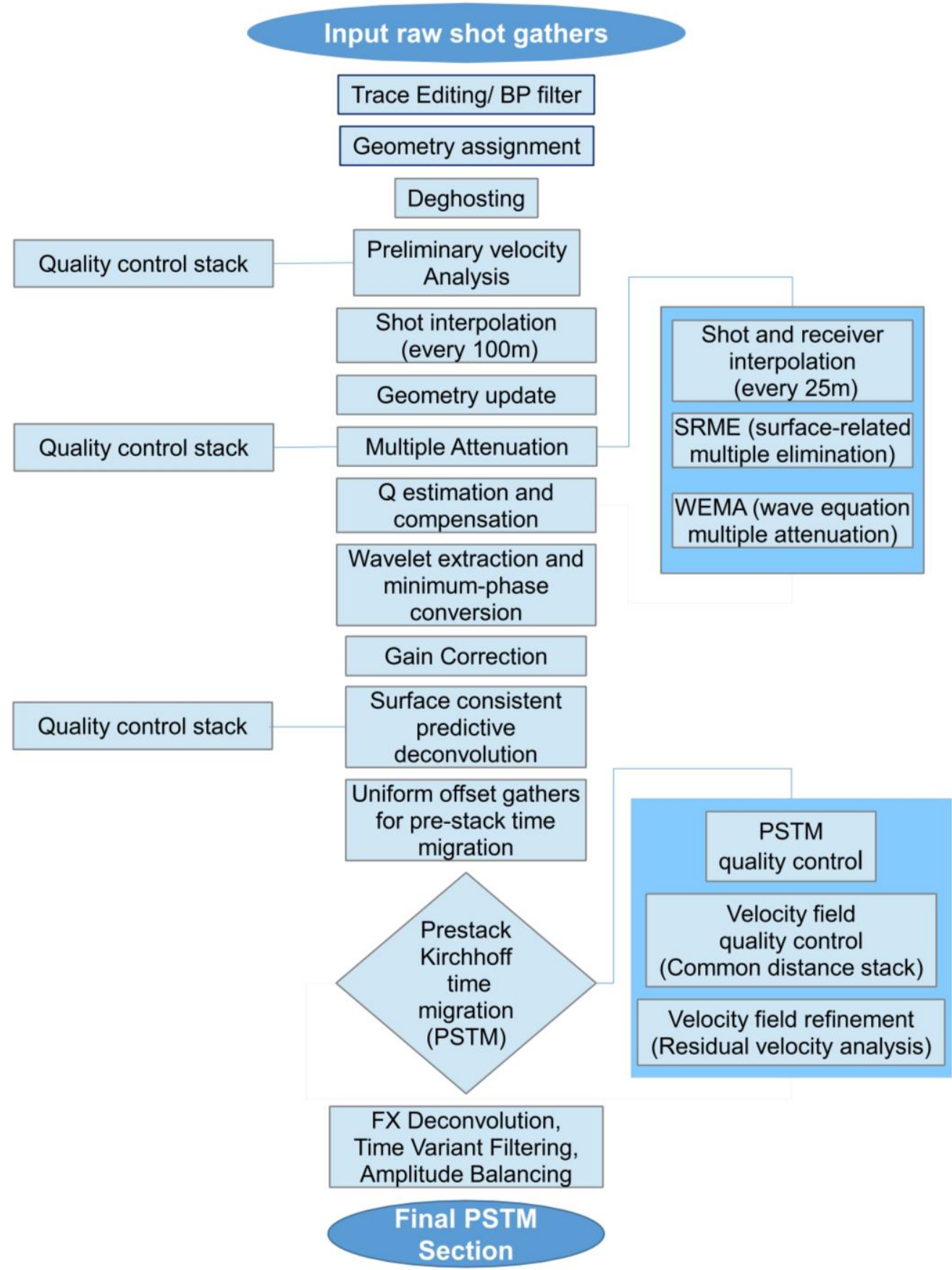

Figure 12.3: The time reprocessing flow chart applied to the MS-29 profile in this study. 


\subsubsection{Editing}

The MS data were acquired in analogue mode (on 21 and 9-track magnetic tapes), subsequently transcribed into 3480 cartridges and then stored on a RAID hard disk storage system. During the transcription of the data, some problems involving very large amplitudes (spikes) arose, affecting the raw traces. To remove the spikes, we implemented a C-language program that identifies the anomalous amplitudes and replaces them with the average amplitudes of the neighbouring samples. For our specific problem, the code removed all spikes without affecting the large amplitude signals (Figure 12.4).
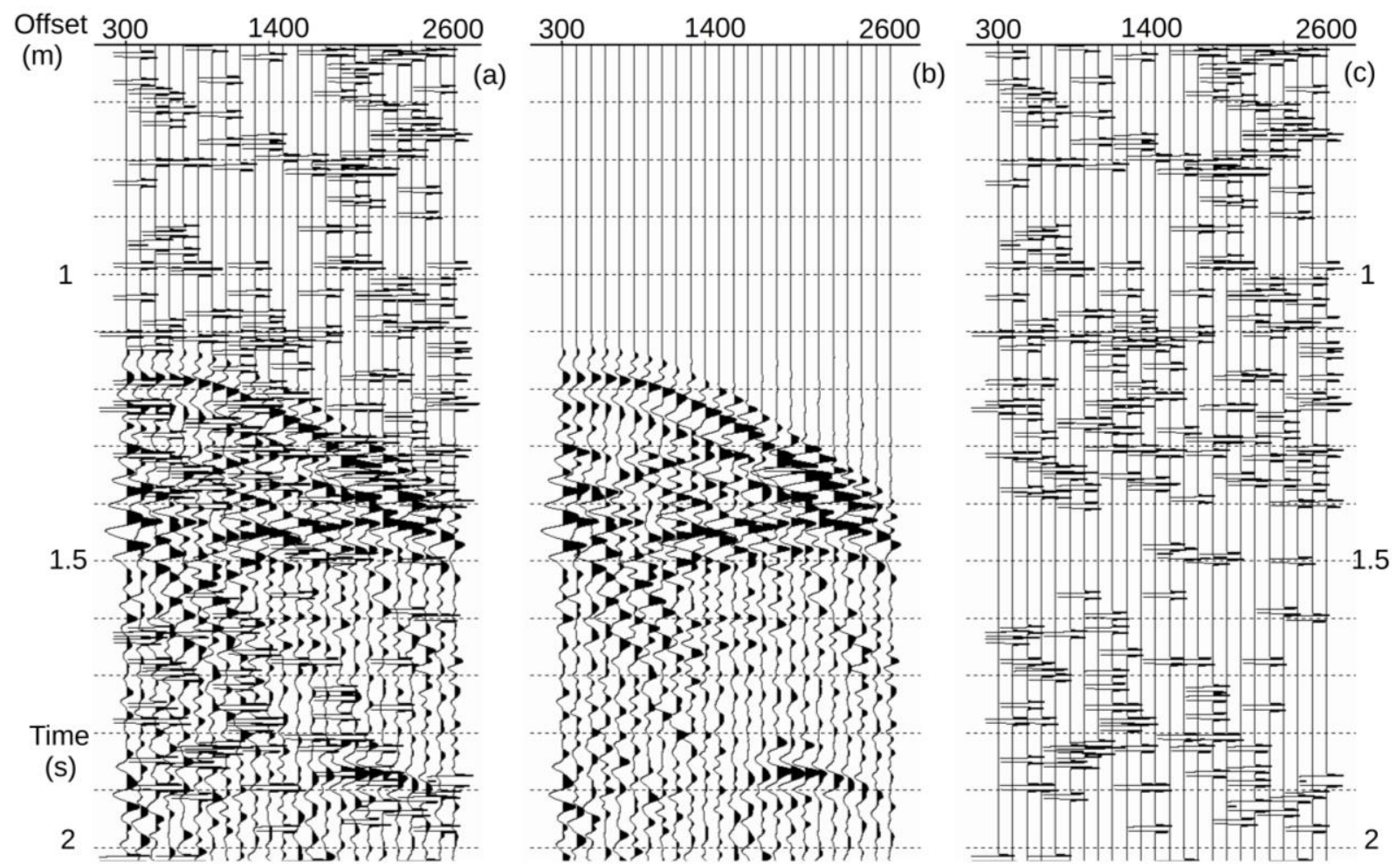

Figure 12.4: An example of a shot gather affected by spikes (a), after spike removal (b) and the difference between ( $a$ ) and (b), which shows all the spikes removed (c).

Some preliminary mandatory operations were then applied to the data, such as quality control and geometry assignment. In particular, to take into account missed shots, the correct shot number was assigned to the field record number gather (FFID) reported on the original observer logs. To remove bad records and noisy traces, data editing was performed. Finally, the geometry has been defined and assigned according to the acquisition configuration, reported on the original observer logs (minimum offset, cable length, receivers and shots spacing). We picked the water bottom on the near trace section and extrapolated it to all other offsets in the shot gathers, using the Pythagorean Theorem. We took advantage of the water bottom picks in several processing steps: we muted the direct and refracted wave arrivals on the shot gathers based on it, we used it in the multiple removal step to find the first water bottom multiple, and we used it to define autocorrelation windows for 
the deconvolution step. Finally, we also used the water bottom picks for designing the application windows of the time-variant filtering. After trace editing and geometry assignment, a band-pass filter was applied to remove the very low and high-frequency noise affecting the data.

\subsubsection{Deghosting}

In recent years, deghosting has become a key step in broadband processing (Zhou et al., 2012), not only for modern data but also for legacy data (Zhou et al., 2015). The undesired ghost events reduce the frequency bandwidth, causing a loss of low frequencies and a frequency notch filter effect

estimated with the formula $f_{\text {notch }} \frac{V_{\text {water }}}{\lambda}$, where $\lambda$ is twice the receiver or source depth and $V_{\text {water }}$ is the speed of sound in the proximity of the sea surface. Since receivers and source depths play a key role in the nature of the ghost, knowledge of their correct positions for every shot is fundamental. In modern acquisition surveys, these depths are measured and well known, but for legacy data some uncertainties arise (Zhou et al., 2015). In our case, we recovered the depths from both the observer log and frequency spectrum analysis (Dragoset, W.H., 1990), considering an error range that we included in the following deghost step. Analyzing the frequency spectrum of the MS-29 seismic data, a clear notch is detectable at about $30 \mathrm{~Hz}$ (see Figure 12.5c); this is due to the receiver cable depth ( $25 \mathrm{~m}$ below the sea level). The other notch, expected at about $50 \mathrm{~Hz}$ (equivalent to the source depth at $15 \mathrm{~m}$ b.s.l.), is not recognizable since it falls at the upper range of the frequency spectrum. We used a deghosting operator which, working in the frequency domain, recovered the ghost-free wavefield by minimum energy criteria (Yilmaz and Baysal, 2015). The ghost-free frequency spectrum shows an overall increase in the frequency bandwidth, especially around the $30 \mathrm{~Hz}$ notch frequency (Figure 12.5c). The section benefits from the overall frequency improvement, showing higher resolution (see the water bottom reflection and the high amplitude reflector at about $1.7 \mathrm{~s}$ TWT in Figure 12.5a and 12.5b) and the removal of ghost reflections. 


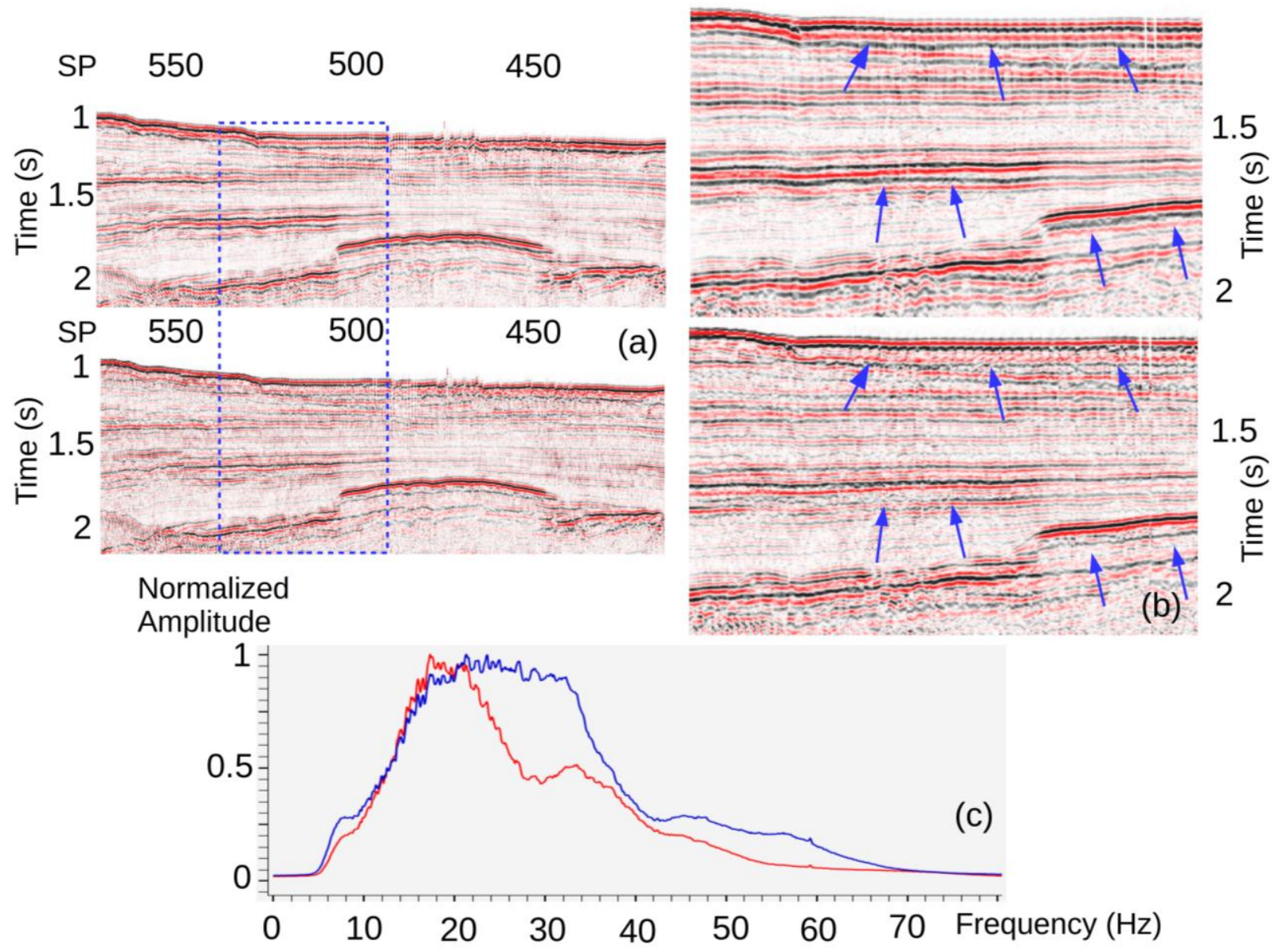

Figure 12.5: A portion of the stacked section before (a, upper) and after the deghost step (a, lower). The dashed blue rectangle area is shown larger in (b) to better highlight the improvements to the reflections, which are pointed out by the arrows in $(b)$. The comparison between the frequency spectrum before (red line) and after deghosting (blue line) is also shown (c).

\subsubsection{Data Interpolation}

After deghosting, the data were interpolated to reduce aliasing related issues which adversely affect surface-related multiple elimination (SRME) and PSTM. This procedure was applied in two steps:

1) The fold coverage was incremented from 600 to $1200 \%$ by inserting an interpolated shot gather between every two original shots, thereby decreasing the shot spacing from $200 \mathrm{~m}$ to $100 \mathrm{~m}$. This new dataset has become the input for all the further processing sequences (including time and depth migration).

2) To apply the SRME technique, the data were further interpolated (as suggested by Verschuur, 2013); this operation was performed in order to obtain a dataset with equally spaced shots and receivers $(25 \mathrm{~m}$ ). After the SRME application, we removed the extra interpolated data, coming back to the first step interpolated data. 
Among the different interpolation techniques available, we chose the so-called local-slant stack method. In practice, this algorithm calculates the coherence of the input data for a certain given spatial gate (number of input traces) and reflection dip range. The coherence is used to determine how many dips should contribute to estimate the interpolated data between two nearest input traces. The choice of the dip parameter is fundamental and so an accurate analysis of the input data is necessary to find the right range of dips. We analyzed the interpolated gathers to look for unrealistic reflections and we compared the frequency spectra before and after the interpolation. The major reflections (Figure 12.6a) were correctly estimated and the amplitude spectrum is very close to the original one (Figure 12.6b).

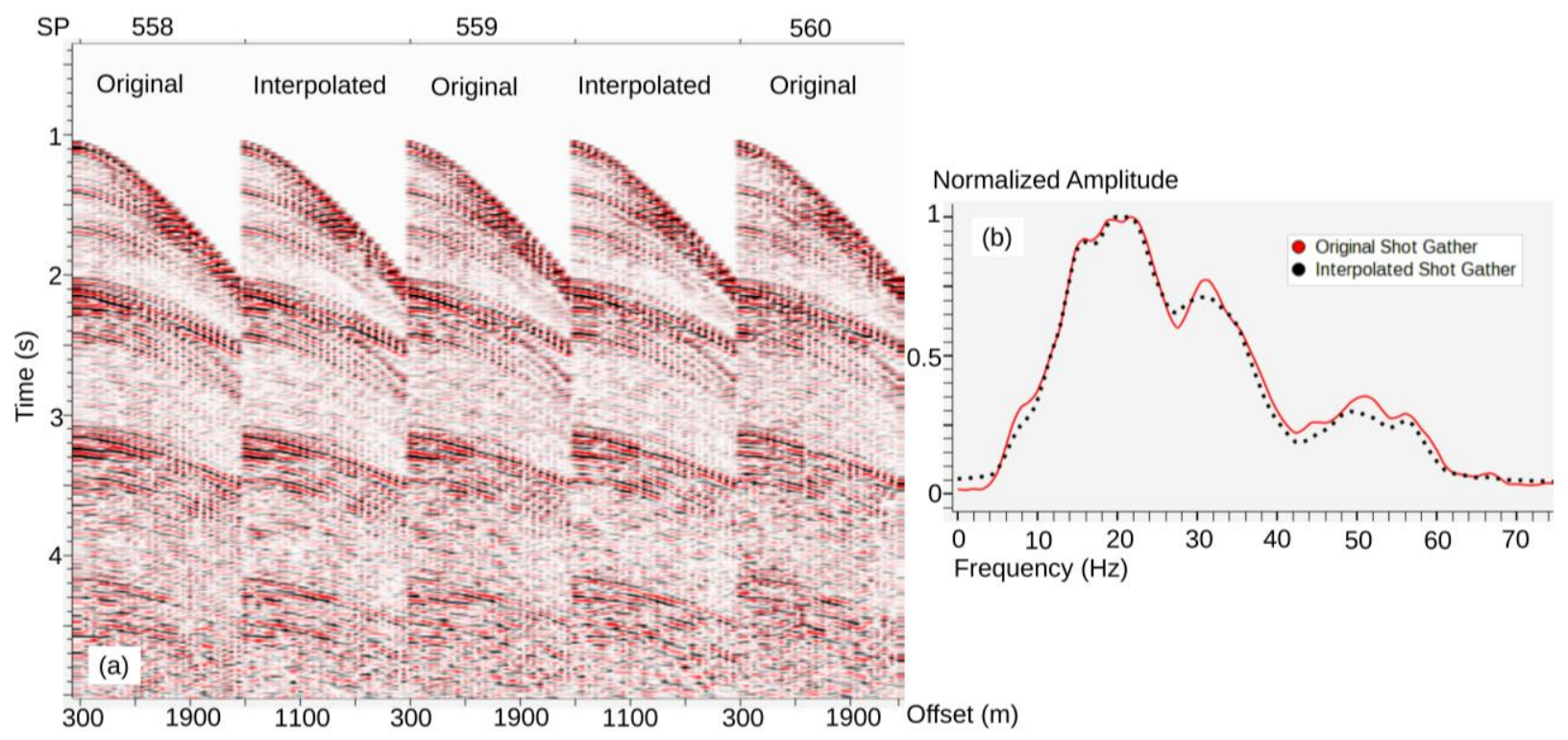

Figure 12.6: Comparison between original and interpolated shot gathers (a) and their respective frequency spectra $(b)$.

\subsubsection{Multiple attenuation: SRME and WEMA}

In marine seismic data processing, multiple attenuation is an important operation and many different methods have been developed over the years. Simplifying things, these methods fall into three main approaches. The first approach attempts to distinguish primaries from multiples based on their different properties (such as periodicity or velocity). The second approach includes waveequation based methods to predict multiples. The third approach is to predict multiple directly from the data. Surface-related multiple elimination (Verschuur et al., 1992) belongs to the last approach (a so-called data-driven method). The process is achieved by a mathematical manipulation of recorded seismic data without any knowledge of the investigated geological context. This gives SRME a great advantage over the other methods where some knowledge of geology is required. In practice, SRME achieves multiple attenuation through two main steps: first, the surface-related multiples are predicted by a convolution process of the seismic records, and then the modeled multiples are adaptively subtracted from the original data (usually by a least-squares matching filter, Abma et al., 2005). The adaptive subtraction is needed due to some imperfection arising in the 
multiple modelling process, due to factors such as poor or absent wavelet knowledge, the sampling recording interval and the limitation of the 2D assumption. Low spatial data sampling with inherent aliasing problems adversely affects the quality of multiple attenuation by the SRME method.

As a first attempt, we applied SRME on the original, not interpolated data (600\% fold coverage), using the algorithm implemented in the Echos software (Figure 12.7 and 12.8). This code attempts to compensate for irregular geometry, filling in missing shots by replacing them with nearby ones (in order to have shots and receiver spacing equal to $100 \mathrm{~m}$ ). Even with this compensation, the modelled multiples are of poor quality (Figure 12.7d) and consequently, after SRME application, the multiples are still visible on the gathers (Figure 12.7b) and the stacked section (Figure 12.8b). To overcome the aliasing problem, we used the interpolated shots and receivers (in order to have the same $25 \mathrm{~m}$ spacing) for SRME. The resulting modelled multiples are clearly imaged with a drastic increment of resolution (Figure 12.7e). In particular, the multiples no longer show the severe spatial aliasing that was due to inadequate sampling. Finally, with this procedure, the stacked section shows a dramatic improvement in multiple attenuation (Figure 12.8c). Any noise introduced in the interpolation process does not affect the results, because interpolated traces are only used to model the multiples and are subsequently removed.

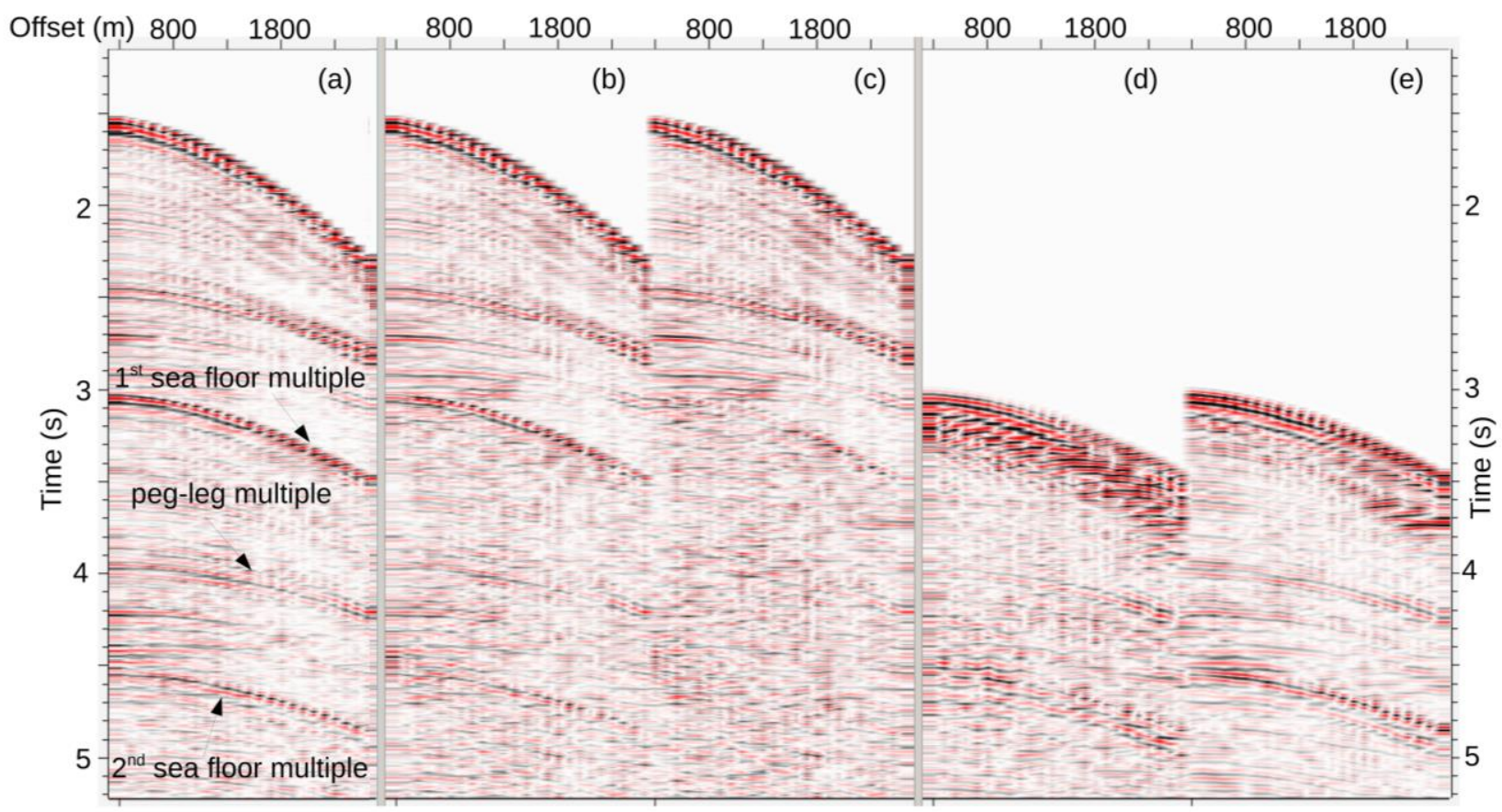

Figure 12.7: A shot gather before (a) and after SRME, applied respectively on the original data (b) and on the interpolated data (c). The SRME modeled multiples are shown on the original data $(d)$ and on the interpolated data (e). 

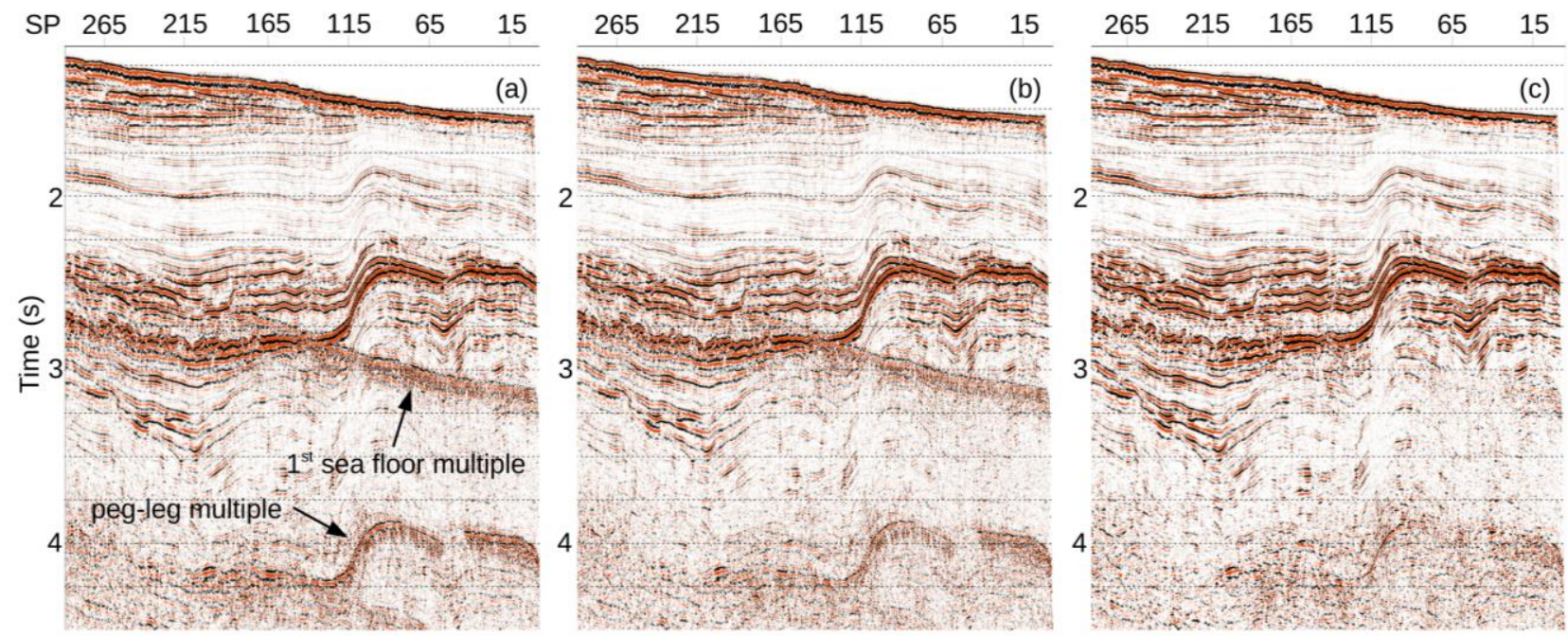

Figure 12.8: Portion of a stacked section before (a) and after SRME, applied respectively on the original data $(b)$ and on the interpolated data $(c)$.

Since residual multiples were still present after SRME, we also applied wave equation multiple attenuation (WEMA). Multiple reflections that are generated by the water bottom in marine seismic data can be predicted by a combination of numerical wave extrapolation through the water layer and estimation of the water-bottom reflectivity (Wiggins, 1988). Attenuation of the multiples occurs when the predicted wavefield is subtracted from the original record. WEMA performs multiple modelling and adaptive subtraction by the downward continuation of the receivers to the multiple generating water bottom and upward continuation of the receiver field by the same amount. This is followed by adaptive subtraction and receiver continuation back to the original receiver depths. WEMA further improved multiple removal in some areas of Line MS-29, while preserving the primary signals (Figure 12.9).
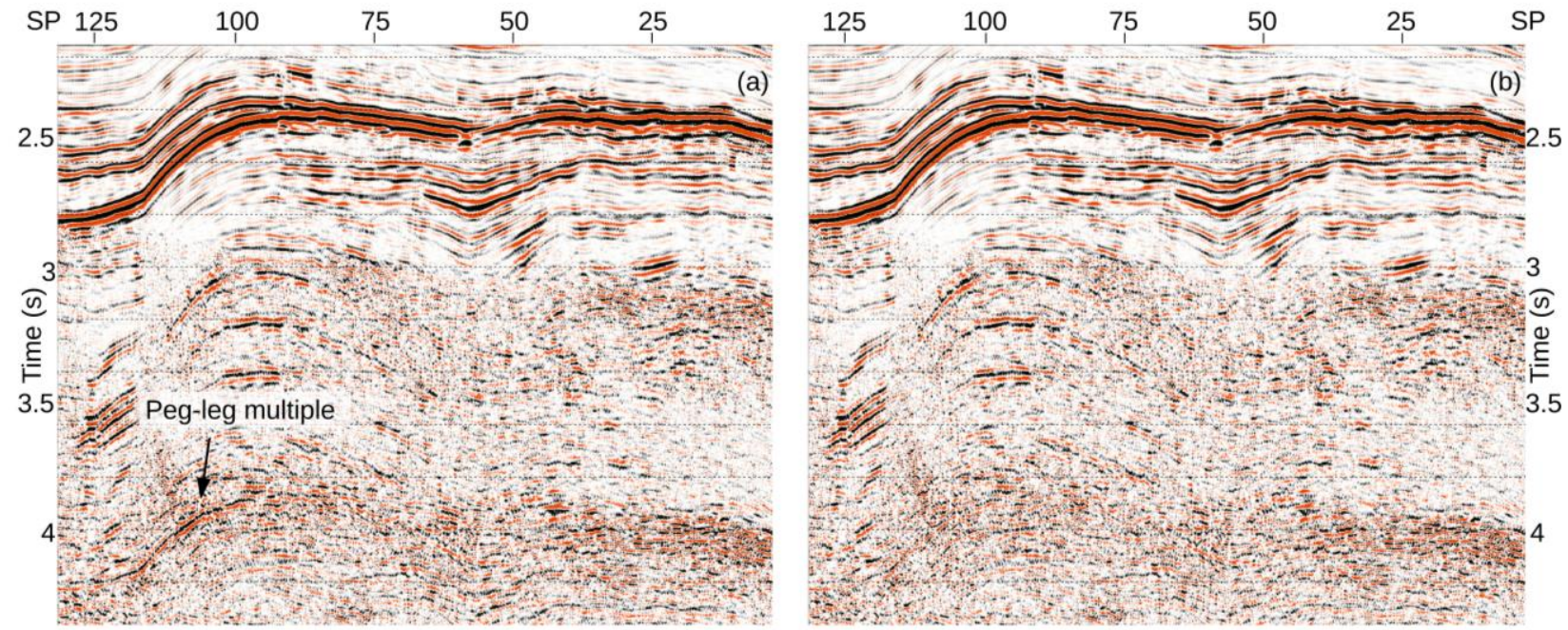

Figure 12.9: Comparison of a portion of the stacked section before $(a)$ and after $(b)$ the application of the WEMA method. 


\subsubsection{Q Correction}

A seismic wave traveling through a medium is affected by intrinsic attenuation due to friction between the fluid and solid particles. The attenuation phenomenon can be quantified by the dimensionless quantity $\mathrm{Q}$, defined by $Q=2 \frac{\pi E}{\Delta E}$, where $\mathrm{E}$ is the energy of the seismic wave and $\Delta \mathrm{E}$ is the variation in energy over a time span that is equivalent to one cycle of a frequency component of the waveform (Kjartansson, 1979). This absorption effect (anelastic attenuation) can lead to the disappearance of the seismic wave. A Q Correction is applied to remove the effect of viscoelastic wave propagation on both amplitude and phase of seismic reflection data (i.e. attenuation and dispersion) (Hale, 1981; Hargreaves and Calvert, 1991; Wang, 2008; Van der Baan, 2012). Inverse $\mathrm{Q}$ filtering is a wave propagation-reversal procedure that compensates for the energy absorption and corrects the wavelet distortion in terms of the shape and timing, to produce a seismic image with higher resolution (Wang, 2008). This is achieved by boosting the attenuated high frequencies while reducing the small travel-time variation between low and high frequencies.

To reduce the absorption effect, a series of time-varying $\mathrm{Q}$ functions have been estimated by analysing the amplitude decay on a stacked section and considering the obtained values as a function of the propagation time $(\mathrm{t})$, i.e. $\mathrm{Q}(\mathrm{f}, \mathrm{t})=\mathrm{Q}(\mathrm{t})$, following the method proposed by Wang, 2004.

Therefore, to compensate for the anelastic attenuation, the applied algorithm considers a nonstationary convolution approach: $s(t)=r(t) * w(t) * h(t, \tau)$, where $\mathrm{s}(\mathrm{t})$ is the seismic trace, $\mathrm{r}(\mathrm{t})$ is the reflectivity, $\mathrm{w}(\mathrm{t})$ is the wavelet and $\mathrm{h}(\mathrm{t}, \tau)$ is the time-varying $\mathrm{Q}$ filter (Wang, 2008).

\subsubsection{Wavelet extraction and minimum-phase conversion}

Minimum-phase is a fundamental condition for statistical deconvolution. As such, we need to extract the representative wavelet from the seismic data and then convert them into the minimumphase equivalent to proceed with the deconvolution operation (Yilmaz, 2001).

The algorithm applied to convert the signal into its minimum phase equivalent designs and applies a wavelet shaping filter to each ensemble without any assumptions about the phase of the source wavelet. The representative wavelet is estimated and extracted in the cepstral domain representation of the signal (i.e. the inverse Fourier transform of the logarithm of a signal's Fourier transform; for more details see Oppenheim and Schafer, 1975; Tribolet and Quatieri, 1979; Ulrych et al., 1995).

A shaping filter to transform the extracted wavelet into its minimum-phase equivalent is computed using the least-squares procedure (Robinson and Treitel, 1980). The filter is then applied to all traces of the ensembles. Figure 12.10 shows the overall effect of both Q correction and minimum phase conversion, together with surface consistent deconvolution.

\subsubsection{Surface Consistent Deconvolution}

To take into account amplitude, frequency and phase variations in the source signature, a predictive surface consistent deconvolution (SCD) has been applied to the data (Levin, 1989). The effect of high amplitude random noise leaking into the deconvolution operator causes most wavelet instability problems (Prakash et al., 1998). The surface consistent hypothesis considers the seismic trace as the convolution of a source operator, a receiver operator, a reflectivity operator and an offset related operator.

Application of SCD on vintage data leads to great improvement in data quality by reducing random noise, removing the variation of amplitudes due to source signature irregularities and improving 
vertical resolution (Figure 12.10). To design the gap length and the operator length we performed a series of tests, varying these parameters and time gates for the autocorrelation computations. The parameters producing the best results in terms of improved vertical resolution (spectral whitening), noise reduction and amplitude balancing were chosen. After several tests, we chose the second zero crossing of the autocorrelation function $(24 \mathrm{~ms})$ and a $144 \mathrm{~ms}$ operator length.

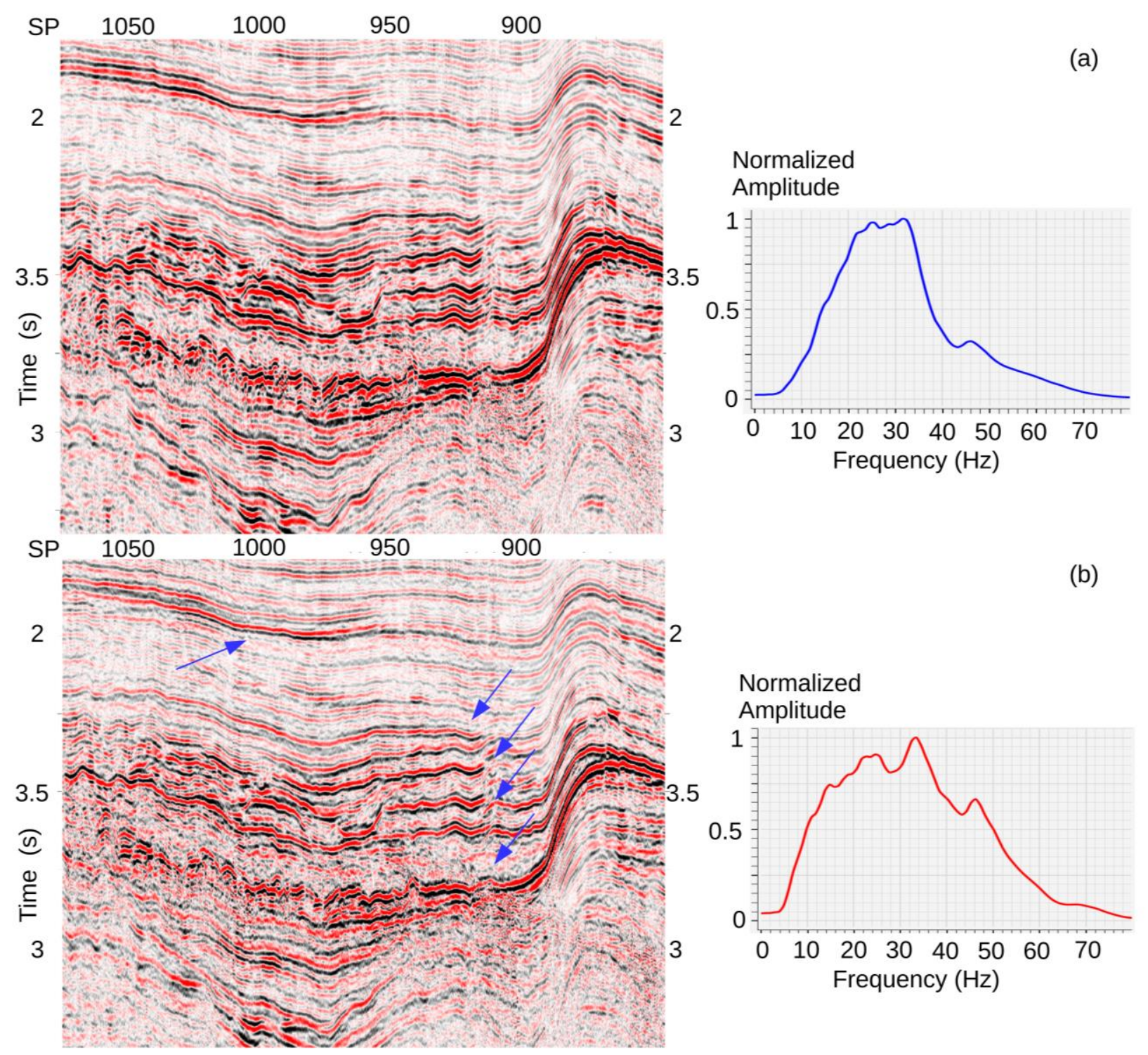

Figure 12.10: Portion of the stacked section before (a) and after the application of $Q$ correction, minimum phase conversion and surface consistent deconvolution $(b)$ with the respective frequency spectra. The blue arrows point out the resolution improvements on the main reflections. 


\subsubsection{Pre-stack time migration}

In seismic processing, migration is one of the fundamental steps that lead to obtaining an image of the subsurface from the recorded data. Migration moves dipping reflectors to their real subsurface positions and collapses diffractions, thereby increasing the spatial resolution (Yilmaz, 2001). With increasing geological complexity, the type of migration has to change from post-stack to pre-stack and from time to depth domains. PSTM can handle reflectors with conflicting dips, but it fails in the presence of lateral velocity variations (it is a 1D approximation). Therefore, in these cases, PSDM is required. The different migration schemes can be categorized into two classes: the integral methods (which includes the Kirchhoff migration) and the differential methods (which includes wavefield extrapolation migration, WEM, and reverse time migration, RTM). Put simply, the first migration class uses ray theory to describe the motion of a wavefront (ray methods), while the second one extrapolates the wavefield (waves methods). Sometimes the ray methods are described as high-frequency approximation methods (Jones, 2010). As a matter of fact, ray theory is an efficient approximation of a moving wavefield as long as the scale order of the seismic wavelength is large in relation to changes in the velocity field. The great advantage of ray methods, such as Kirchhoff migration, is that they produce easily migrated gathers, allowing iterative refinement of the velocity field by means of residual velocity analysis. Therefore, considering the geological complexity imaged by the MS-29 lines and the seismic resolution of these vintage data, we decided to use the pre-stack Kirchhoff migration, paying attention to the aliasing problems related to low fold coverage.

Three types of spatial aliasing could affect the Kirchhoff migration: image aliasing, operator aliasing and data aliasing (Lumley et al., 1994). Image aliasing is only an aesthetic problem that can be easily avoided with an appropriate output sampling of the image space. Operator aliasing occurs when the migration operator summation trajectory is too steep for a given input seismic data spacing and frequency content. This aliasing is distinct and independent with respect to data aliasing. Therefore, the effects of operator aliasing are mitigated by anti-aliasing filters such as triangle filtering (Lumley et al., 1994). The effects of data aliasing, on all the methods of migration, is largely discussed in Yilmaz (2001). This aliasing occurs when the spacing of the recorded trace is not sufficiently sampled. Looking at our Kirchhoff PSTM section, this effect is clearly shown by the "blocky" (not continuous) appearance of the reflections (Figure 12.11a).

The result is a poor-quality image that is due neither to velocity errors nor to operator aliasing since we applied a medium triangular anti-aliasing filter to the migration. In this case, the aliasing is not specifically due to trace sampling (100 m geophones streamer, $50 \mathrm{~m}$ CMP traces) but is related to the shot spacing $(200 \mathrm{~m})$. To mitigate this problem, we interpolated traces in the common offset domain in order to have a shot placed every $100 \mathrm{~m}$, increasing the fold to 12 and decreasing the CMP offset increment to $200 \mathrm{~m}$.

Moreover, to attenuate the migration noise we inserted a job to regularize the offsets within each CMP. This job applies differential NMOs, correcting each trace for the difference between their original and the uniform offset. In this way, we obtained 12 traces CMPs, with a constant offset range between 350 and $2550 \mathrm{~m}$.

Data aliasing and noise are largely suppressed and reflectors are clearer and more continuous in the PSTM section, with only a light smearing effect introduced (Figure 12.11b). 


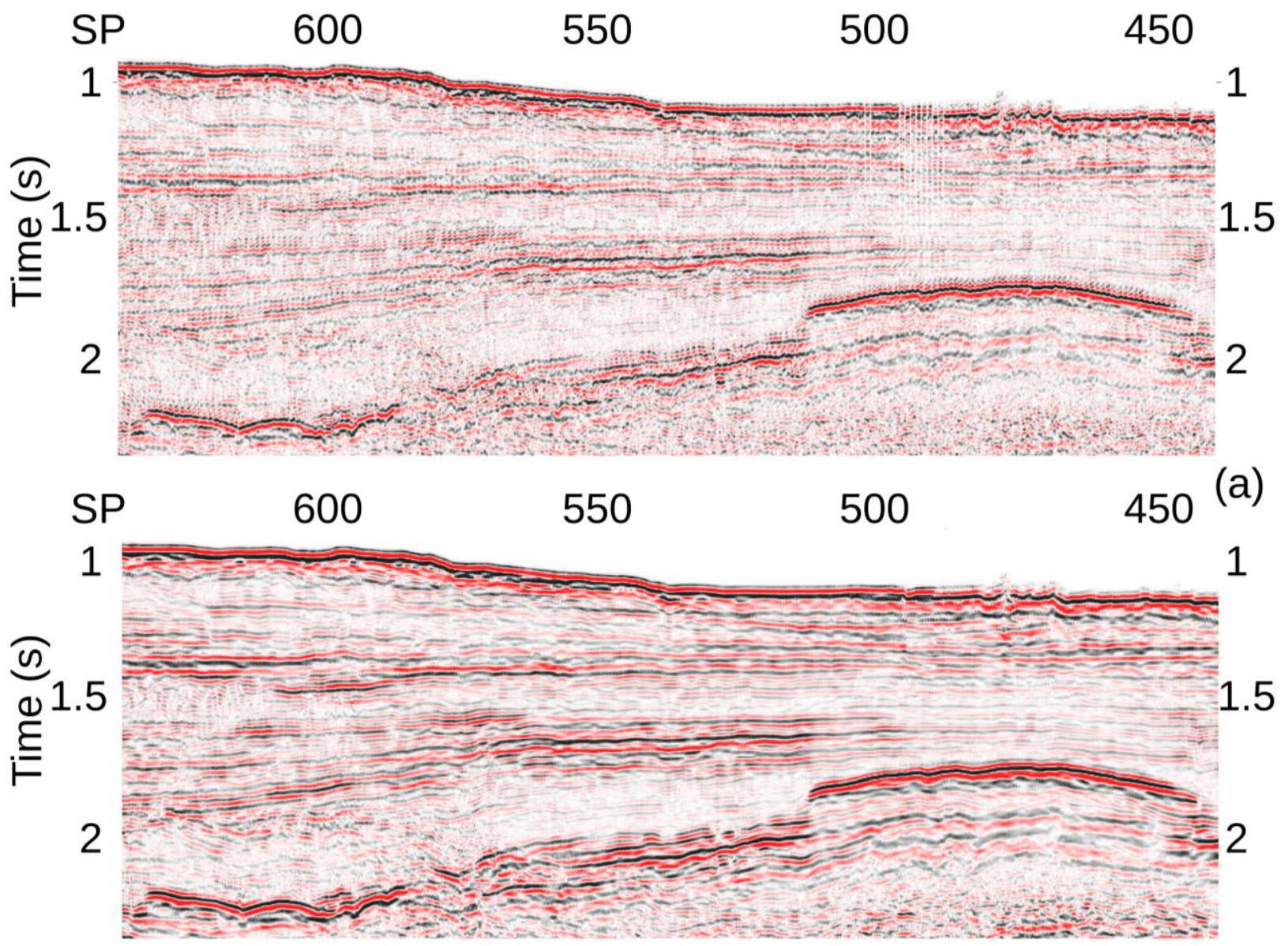

(b)

Figure 12.11: Portion of PSTM section where PSTM was applied without (a) and with (b) shot interpolation. 


\subsection{Ray-based tomography}

The process of seismic imaging through modelling the proper sub-surface velocity structure is a form of inversion of seismic data (Treitel and Lines, 2001), and the term inversion is often used to imply building a velocity model that is improved iteratively until it and the seismic data are optimally in agreement (Weglein and Stolt, 1999). Nowadays, velocity modelling has become a crucial aspect in seismic processing and makes use of tomography methods (Jones I., 2010, 2018) that can be divided into two classes: ray-based tomography and waveform tomography. Put simply, the first class deals only with the travel time information (kinematic approach), while the second also deals with the seismic wave, amplitude and phase (dynamic approach) and it can take into account different types of waves. Ray tomography can resolve velocity variations at a scale much greater than the seismic wavelength. For example, if we consider a wavelength of $30 \mathrm{~m}$ (i.e. velocity of $1800 \mathrm{~m} / \mathrm{s}$ for the Plio-Quaternary sediments below the seafloor and a maximum signal frequency of $60 \mathrm{~Hz}$ ), the resolution limitation will prevent us from determining velocity variations less than about $150 \mathrm{~m}$. To determine velocity variations smaller than the wavelength, ray theory (and Snell's law) are no longer satisfactory; full waveform inversion approaches are required. For many geological contexts (where the scaled velocity anomalies are large and where we do not deal with shallow water or sub-salt areas), the ray tomography allows obtaining acceptable results at comparatively low-cost processing.

The ray-based tomography technique aims at finding an interval velocity distribution that minimizes the difference between the calculated travel times (through the ray-tracing) and the observed travel times in the data. Ray tomography is an inverse method and the math involved, which is beyond the scope of this chapter, is discussed at length in the literature (i.e. Yilmaz, 2001). Here, we describe some general concepts. In matrix notation, the tomography problem is described by $T=D S$, where $\mathrm{T}$ is the wave's travel-time matrix, $\mathrm{D}$ is the matrix of the ray paths and $\mathrm{S}$ is the slowness matrix (the inverse of the velocity, the unknown variables). To obtain the slowness distribution, the system needs to be inverted, but since the matrix D is generally not invertible, both sides of the equation are multiplied by the transpose of D (DT), obtaining $D^{T} T=\left(D^{T} D\right) S$. The matrix DTT (which is called the symmetric square covariance matrix) is square and can be inverted, leading to a system that yields the best solution in a "least square sense", $S=$ $\left(D^{T} D\right)^{-1} D^{T} T$. Typically, this system is solved by a direct solver or using iterative solvers like the conjugate gradient method (Hestenes and Stiefel, 1952).

In practice nowadays, the industry standard is to update the velocity model by ray tomography in the migrated domain (Jones, 2010, 2018). Usually, the velocity update workflow follows an iterative loop, which starts from a first PSDM with an initial smooth velocity model (a guess velocity model). After that, a residual moveout analysis (RMO) is carried out on common image gathers (CIGs) or along selected horizons. If the move-out errors are not acceptable (which means that the reflection events within the CIGs are not sufficiently flat), the velocity model must be updated by the tomography. Re-applying the PSDM with the updated velocity model, the loop restarts and it concludes when the errors become acceptable (compatible with the data resolution). It is important to note that, in the migrated domain, tomography works properly when the guessed starting velocity model is quite close to the final one (within 10-15 \%; Jones, 2010).

Commonly, there are three types of ray tomography, depending on the method used to parameterize the velocity model: grid, layer-based and hybrid tomography (Jones et al., 2007). In grid tomography, the velocities are defined at each of the point on a regular grid. In layer-based tomography, the velocity model is made up of a given number of interfaces and the velocities are 
defined within these interfaces. Moreover, the velocity is the unknown variable of the grid tomography, while velocities and reflectors depths are the unknowns in a layer-based tomography. Grid tomography is preferable, for example, in the case of a sedimentary basin where the velocity changes with depth, due to compaction of the sediments. The layer-based tomography is preferable where the velocity changes sharply at the interface of two lithological units. The hybrid tomography is a combination of these two kinds of tomography, with the strengths of both.

The RMO analysis is, for large datasets, generally performed with an autopicker. There are two ways of considering the RMOs; one refers to a parametric move out (the most common approximations are hyperbolic or parabolic move out), the other to a non-parametric move-out. For simple geological conditions, the parametric move out is a good approximation. In complex geological environments and for small-scale velocity anomalies, move-outs may not show parametric behaviour, meaning the approximation may no longer be valid.

\subsection{Coherency inversion}

Coherency inversion is a method to estimate the layer velocity based on ray theory and in particular on the inversion of the seismic travel-times (Landa et al., 1988; Yilmaz, 2001). This method involves layered model building in the time domain followed by ray tracing to estimate the associated velocities. Starting from a trial velocity, it computes a time to depth conversion of the picked time horizon considering normal-incidence ray-tracing. In this way, the layer base is obtained and it is possible to perform CMP ray-tracing which models the travel time for the entire offset of a CMP gather. Along this modeled trajectory the coherency semblance spectrum is evaluated for the trial velocity adopted (Yilmaz, 2001). Repeating this procedure for a range of potential velocities, it is possible to assign to the layer the velocity which yields the highest semblance at all the CMP locations where the coherency inversion has been performed. Repeating this procedure, the velocity-depth model is built layer-by-layer, from the shallowest to the deepest interpreted horizons. The coherency inversion honours the ray bending at layer boundaries considering a non-hyperbolic CMP travel time ((Landa et al., 1988). This leads to a more realistic initial velocity model compared to that obtained by Dix conversion of the RMS velocity field.

\subsection{The MS-29 velocity modelling and depth imaging}

The geological features shown in the MS-29 seismic line (Figure 12.2) indicate medium to strong lateral seismic velocity variations, due to steep reflectors (carbonate platform surrounded by pelagic sediments), coral reefs, irregular water-bottom topography and gas accumulations. As such, we decided to apply a velocity modelling workflow that can be summarized by three steps:

1) Building a starting velocity-depth model, using the coherence inversion technique;

2) A first velocity refinement loop, using layer-based tomography;

3) A second velocity refinement loop, using grid tomography.

To optimize the tomography results, seismic data need to be free from coherent and incoherent noise. In the time domain, we applied a modern processing sequence to remove the multiples and increase the frequency bandwidth (sub-section 3.2). In order to further increase the signal to noise ratio and to remove the incoherent noise, we used a random noise attenuation (RNA) algorithm in 
three data domains (shot, receiver and offset domain) before starting the velocity model building. Since reliable seismic velocities can be obtained only until depths comparable to the spread length ( $2700 \mathrm{~m}$ in this study), we have made major efforts to improve the velocity model in the central part of the section, where high structural features bounded by steep flanks occur. The tomography and depth migration were carried out with the Geodepth software package (Emerson Paradigm).

\subsubsection{Starting velocity model and layer-based tomography refinement}

To build the first velocity-depth model we interpreted and picked the main horizons on the MS-29 PSTM section, which are: the water bottom, the Quaternary base, two strong reflectors within the Plio-Pleistocene sequence, the Messinian unconformity and the top of the Carbonate Platform. These horizons, representing the more continuous and clearly interpretable reflections in the section, were de-migrated using the RMS velocity field and thereby transformed from the timemigrated domain to the time domain. For this, we performed a layer-by-layer coherence inversion for each horizon, finding the velocity with the highest semblance value. To define a set of trial velocities for the layers, we took advantage of the depth interval velocity field obtained by converting the RMS velocity field used for the PSTM, through Dix's equations (Dix, 1955), and then smoothing it laterally and vertically. The velocity obtained by the coherency inversion was finally smoothed to avoid unrealistic oscillations caused by the noise present in the data (Figure 12.12a).

We performed a first PSDM with the aforementioned velocity-depth model. Thereafter, to check the consistency of our velocity-depth model, we analysed the CIGs, performing a RMOs analysis along the horizons. RMOs represent the input errors for the tomography. At the initial stage of our updating loop, RMO on CIGs were generally high, with areas that showed problems of under (too high a velocity) or over (too low a velocity) corrections (Figure 12.13a). The layer-based tomography updated both the velocity and the depth of the interpreted layers. With the updated velocity field, we re-migrated our data and then repeated the layer-based tomography iteratively in order to minimize the errors and to get the best possible velocity-depth model. The comparison between the CIGs (Figure 12.13) migrated with the starting (Figure 12.12a) and the updated velocity field (Figure 12.12b) shows slight improvement, especially in the shallow part of the seismic data. In particular, the water bottom reflections are well flattened and the RMOs are lower for the reflections just below the sea bottom (compare Figures 12.13b with Figure 12.13a). 


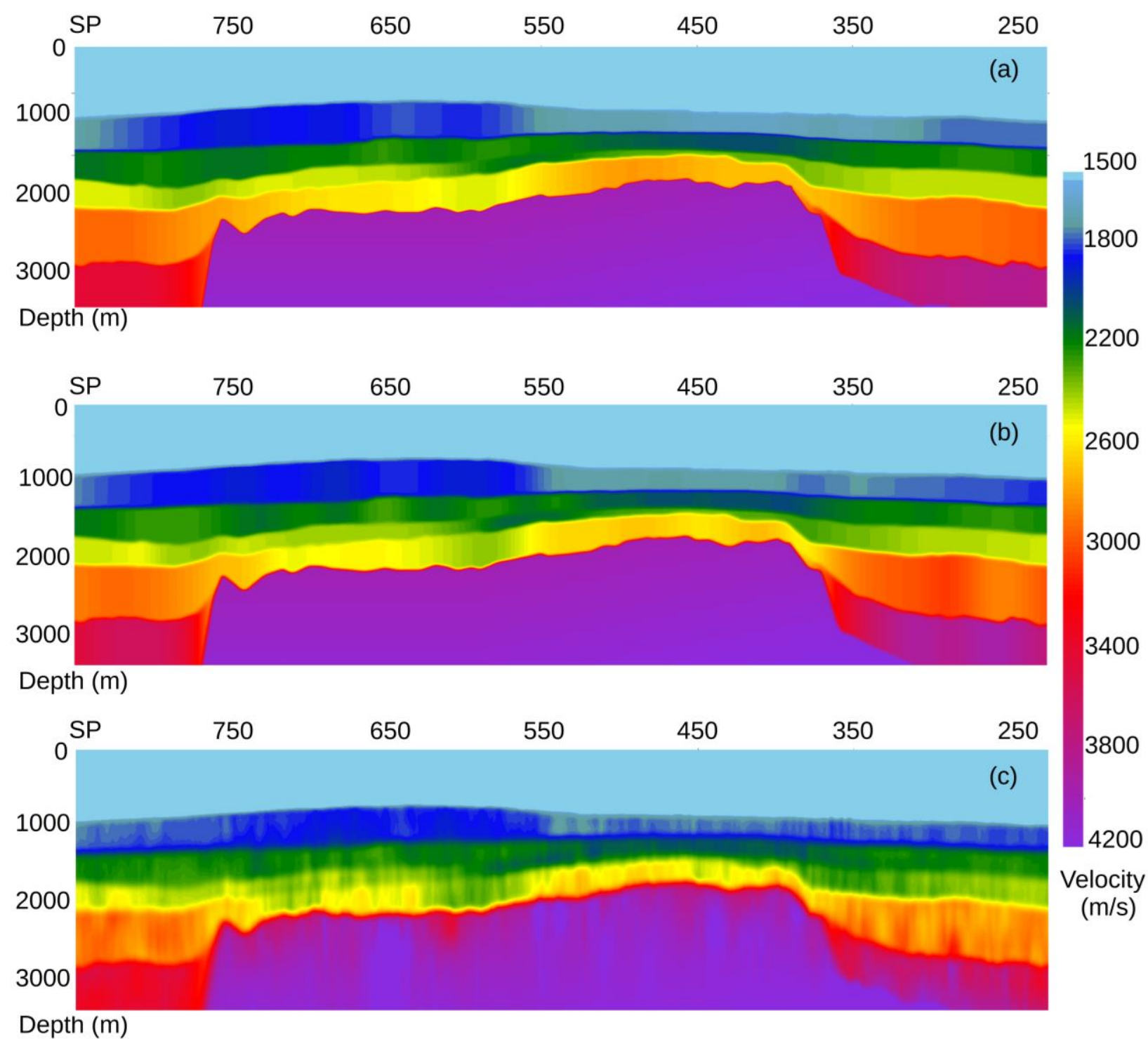

Figure 12.12: The starting interval velocity model obtained through the coherency inversion technique (a). The interval velocity model updated by the layer-based tomography $(b)$. The final interval velocity model refined through the grid tomography $(c)$. 


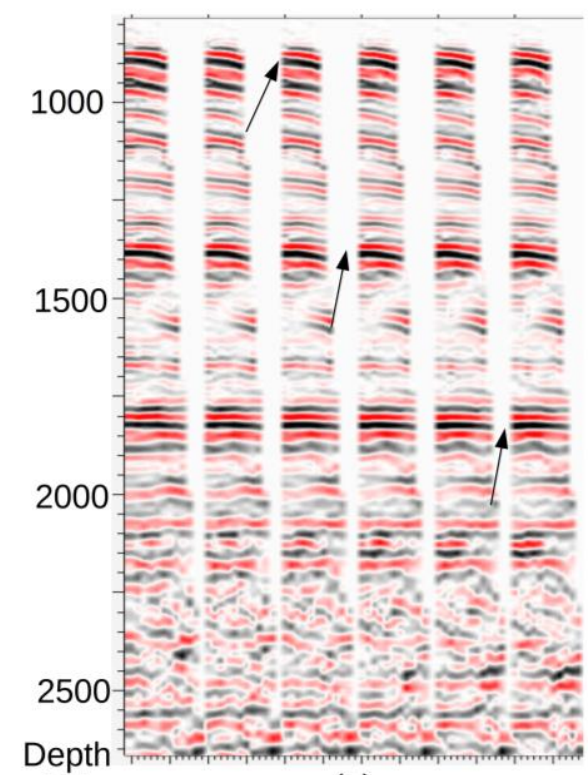

(m) (a)

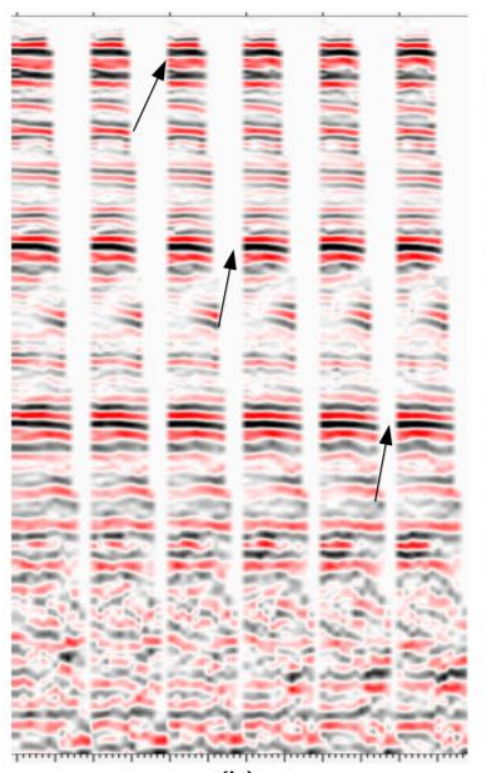

(b)

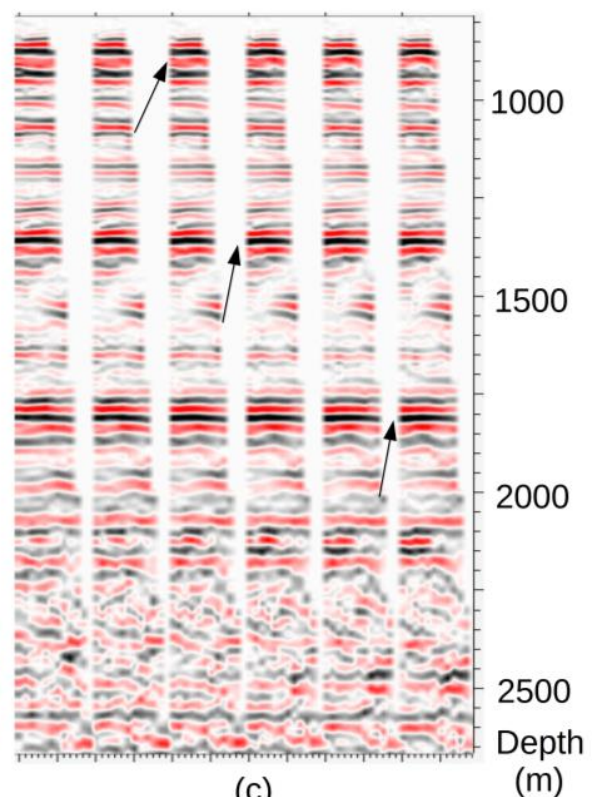

(c)

Figure 12.13: Comparison of CIGs migrated with the starting velocity model obtained through the coherency inversion technique (Figure 12.12a), the interval velocity model updated by the layerbased tomography (Figure 12.12b) and the final interval velocity model obtained by the grid tomography (Figure 12.12c). The arrows indicate reflectors which show high RMO when migrated with the starting velocity field (a), which are progressively flattened with the refinement tomography techniques ( $b$ and $c)$.

\subsubsection{The grid tomography refinement}

In order to further refine the velocity model, we applied grid tomography with an iterative updating loop which can be summarized into three steps:

1) estimation of the structural attributes from the depth migrated section and auto-picking of the RMO errors;

2) application of grid tomography to update the velocity model;

3) PSDM with the updated velocities followed by quality control on CIGs.

During this refinement, the velocity of the first layer (water layer) was kept constant, as the quality control of the seafloor reflections on the CIGs confirmed a reliable water velocity.

In the first step of the grid tomography refinement, we calculated the structural attributes (continuity and dip) on the PSDM section migrated with the velocity model obtained by the layerbased tomography (Figure 12.14), using the Plane Wave Destructor (PWD) method (Claerbout, 1992, Fomel, 2002).

The continuity section shows areas characterized by continuous reflection events and areas with a lack of signal. The structural attributes (in particular the continuity) have two important functions: 1) they are used by the RMOs autopicker and 2) they represent the surfaces from which rays are shot. 


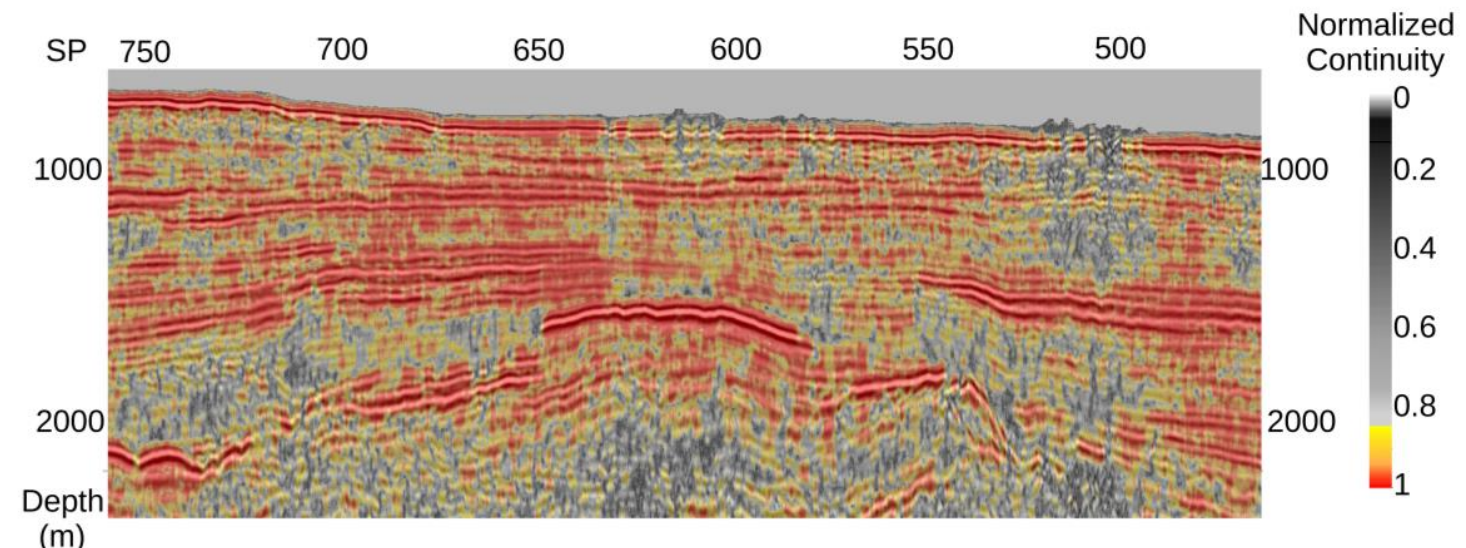

Figure 12.14: The continuity section of the PSDM section obtained with the layer-based tomography velocity model (Figure 12.12b).

To carry out the RMO analysis, we used an autopicker that considers non-parametric move-out, which leads to an improvement of the tomography solution, since it also considers non-hyperbolic move-out (Luo et al., 2014). Moreover, the RMOs were cut at long offsets and shallow depths according to the mute function, and we performed a quality control analysis in order to avoid unrealistic values due to areas of low signal to noise ratio or multiple residuals. The RMO errors, together with the structural attributes, were passed to the grid tomography. The velocity model was discretized into $50 \times 50 \mathrm{~m}$ regular grid while the tomographic problem was solved for a cell size of $200 \times 100 \mathrm{~m}$, respectively for the horizontal and vertical directions.

The final velocity model shows a higher resolution compared to the previous one (Figure 12.12c). The velocity model was accepted on the basis of the flat gathers produced by migration, the spatial correlation between the velocity field and the seismic image, the quality control of the autopicked RMOs, and the verification that some image distortions (like pull-up or push-down) have been well solved (see figure 12.20). 


\section{Results and Discussion}

\subsection{Results from reprocessing}

The final PSTM section, obtained by reprocessing the MS-29 line, shows significant improvements when compared to the vintage version (Figure 12.15). The strong attenuation or, in some cases, complete removal of multiples, is clearly visible in Figure 12.15, and is one of the main result achieved. Moreover, for the first time, we obtained depth imaging of the MS-29 line (Figure 12.19). All of the reprocessing improvements allow for a better interpretation of the profile and the identification of different geological structures and morphologies, as we discuss in detail in this section.

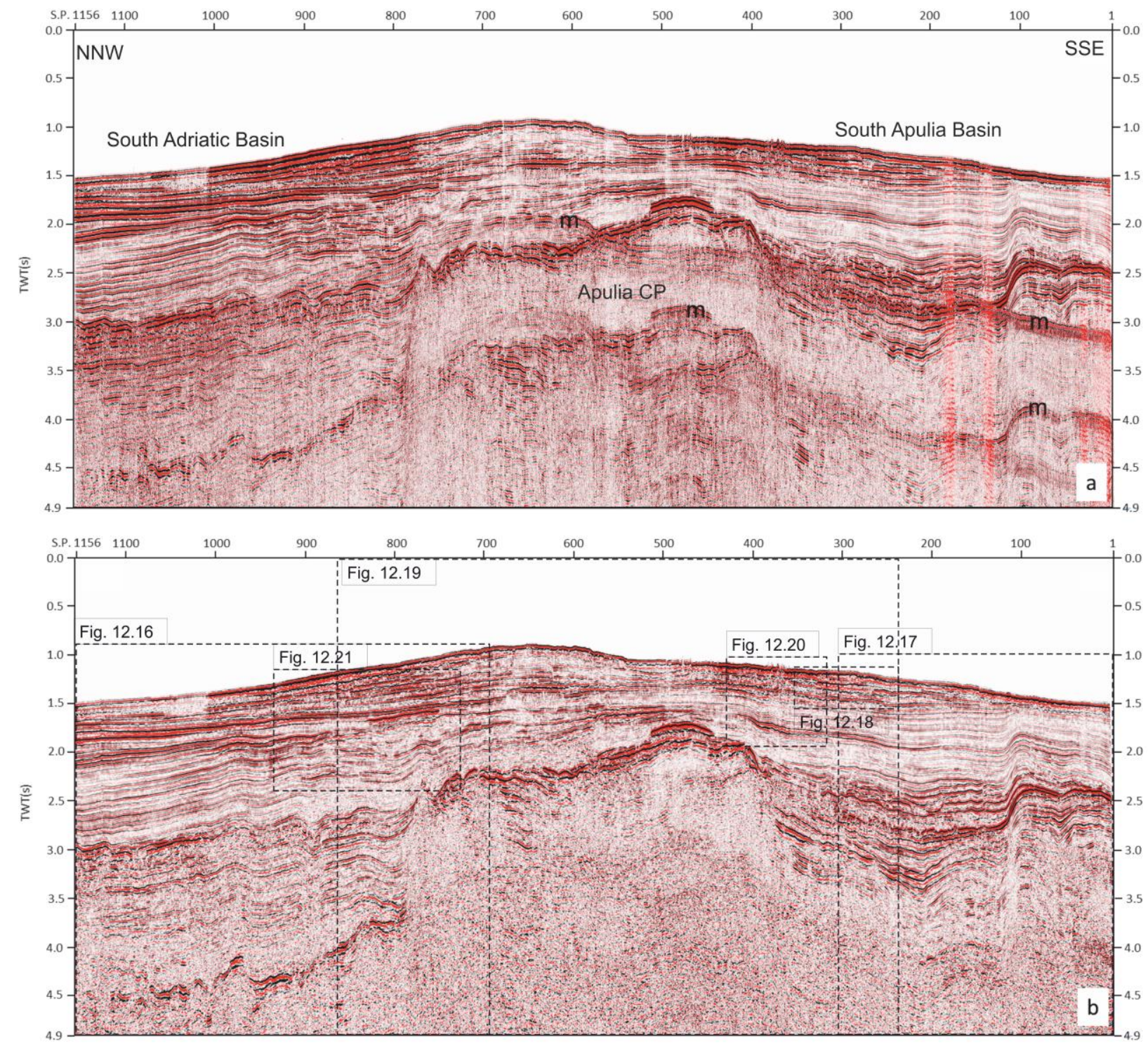

Figure 12.15: The MS-29 seismic section in its original (a) and PSTM final (b) versions. " $m$ " indicates the seafloor multiples related to repeated sea bottom-sea level paths. The Apulia carbonate platform is clearly depicted in the central sector by its opaque seismic facies. It borders 
the South Adriatic Basin to the North and the South Apulia Basin to the South. The two basins are filled by stratified pelagic sequences. For horizontal scale: 100 SP corresponds to $20 \mathrm{~km}$. Note the high vertical exaggeration (approximately $x 26$ for the sea bottom), gradually decreasing with depth.

The broadband processing sequence allowed us to enhance the primary signals, remove coherent and incoherent noise and increase the temporal and spatial resolution. The processing also aimed to preserve real amplitudes by the use of surface consistent deconvolution (sub-section 3.2.7). This led to a clear image of the main reflectors and to a better characterization of the seismic facies. Furthermore, the interpretation of the deformation structures affecting the southern sector of the investigated area are better defined (Figures 12.15, 12.17).

Figure 12.16a shows the northern part of the reprocessed profile, where several features related to the main lithological contrasts are labelled ("MES" for Messinian Erosional Surface, "GS" for Messinian Gessoso Solfifera Formation, "CP" for Carbonate Platform) as well as others that may be related to the presence of gas ("bs" for bright spot, "gc" for gas chimney, "wo" for wipe-outs). The Messinian Gessoso Solfifera Formation, often related to the alternation of gypsum, marl and limestone, is only hypothesized on the basis of the presence of a package of local high amplitude reflectors (Figure 12.16). The envelope seismic attribute (Figure 12.16b), represents the instantaneous energy of the signal, always positive and proportional in its magnitude to the reflection coefficient. The warm colours highlight high acoustic impedance contrast (e.g. bs, MES and GS), while the lower amplitudes (cold colours) probably represent the presence of diffuse gas. 

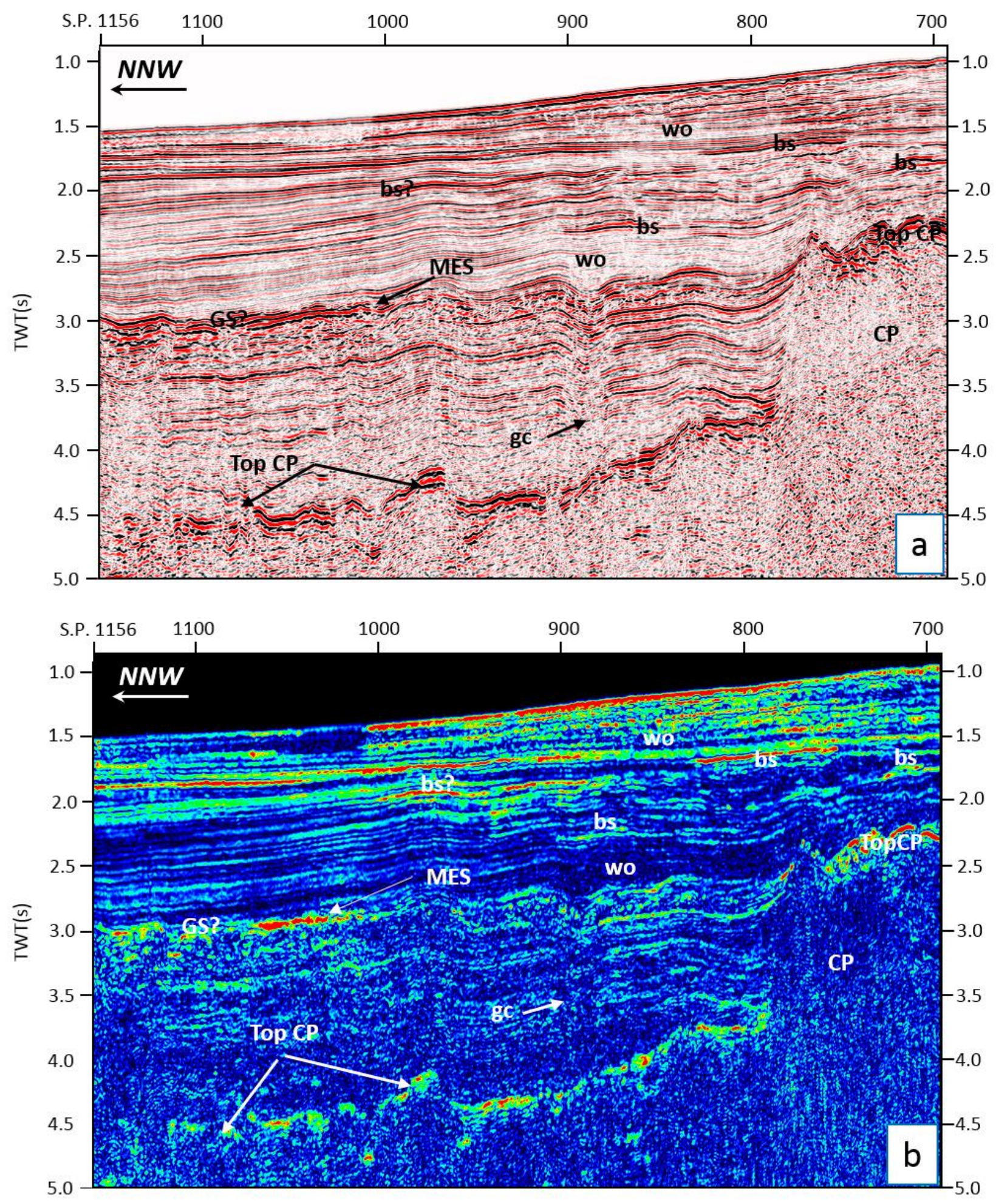

Figure 12.16: Some of the main features highlighted by the applied reprocessing (a) and also visible in the envelope seismic attribute $(b)$, where high contrast of acoustic impedance is highlighted by bright colours: bs, gc, wo, MES, GS and CP. 
Figure 12.17 highlights the southern part of line MS-29, with both the previous (a) and PSTM reprocessed (b) versions. The water bottom multiples affect the vintage section, crossing the primary reflections and hampering the interpretation. The improved lateral continuity and resolution of the signals in (b) make it possible to follow the main reflections related to the basinal high amplitude sequence, which are more evident toward NNW, between 2.3 and $3.3 \mathrm{~s}$ TWT. Inside this sequence is a chaotic semi-transparent unit that we interpret as a buried mass transport deposit (mtd).
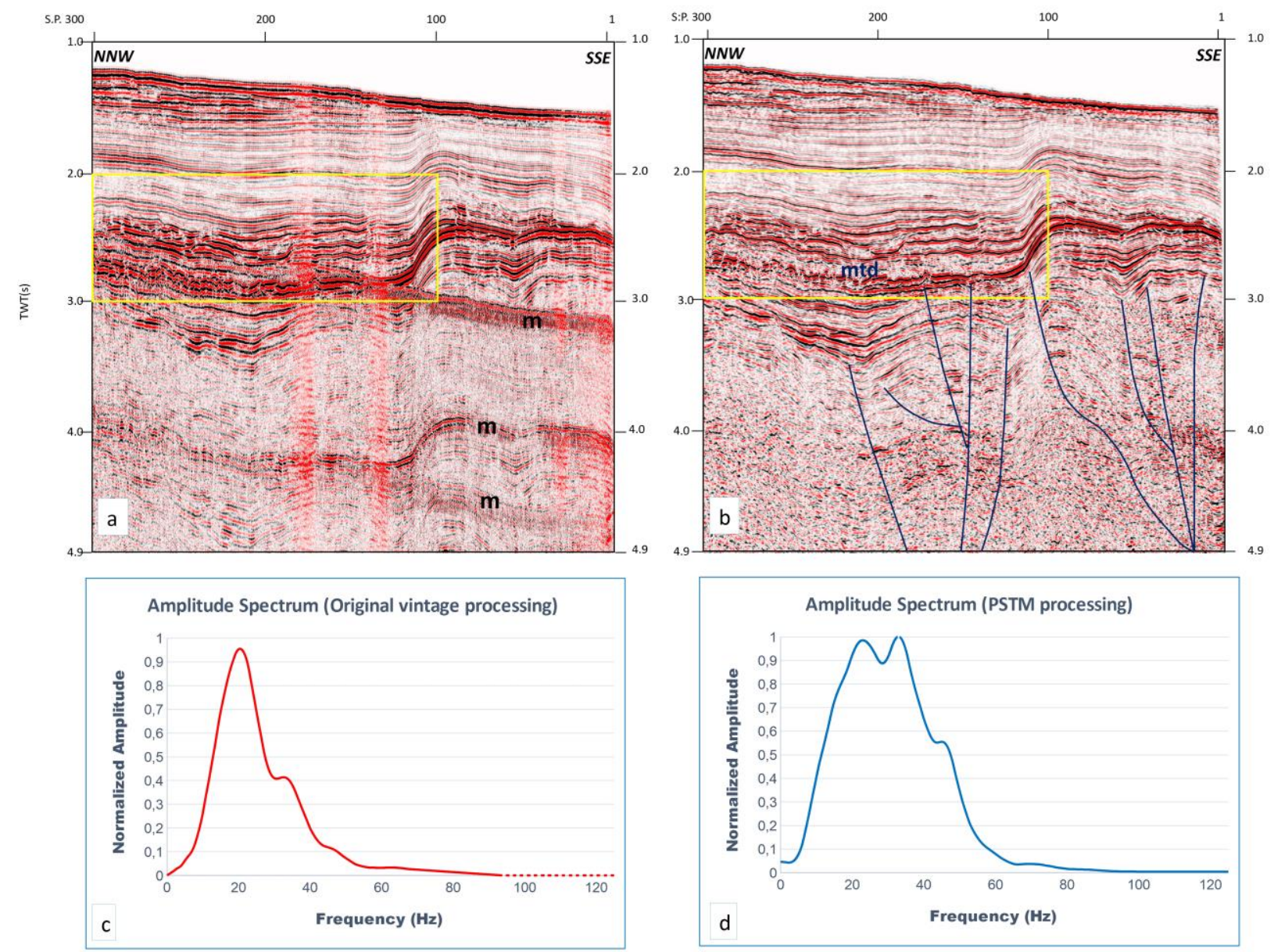

Figure 12.17: Portion of the original vintage section (a): residual of multiple ( $m$ ), heavily present in the section, masks the primary signal. The reprocessed PSTM section (b) shows the multiple removal and improvement of the primary signal. Also thanks to an increase in seismic resolution, it allows better detection of the mass transport deposit. The higher vertical resolution obtained is evidenced by the comparison of the amplitude spectra, that were computed within the area enclosed in the yellow rectangles before $(c)$ and after $(d)$ reprocessing.

The velocity modelling (with the coherency inversion and two tomographic approaches, as described in sub-section 3.5) allowed us to achieve a reliable interval velocity model down to about $3000 \mathrm{~m}$ depth (Figure 12.12c) and to perform PSDM for the central part of the MS-29 (SP 240862, maximum depth $5 \mathrm{~km}$ ). 
In the final velocity model (Figure $12.12 \mathrm{c}$ ), sediments are characterized by a broader range and variability of velocities (between $1600 \mathrm{~m} / \mathrm{s}$ and $3000 \mathrm{~m} / \mathrm{s}$ ), while the carbonate basement starts with velocities higher than $3800 \mathrm{~m} / \mathrm{s}$. In the shallow parts, the velocity field reveals areas with relatively high velocity, due to particular features such as coral mounds (as testified by dredging analogous structures in the same area, Romeo et al., 2011) and areas with a relatively low velocity that could be related to gas accumulations.

Between SP 300 and 550, the shallow sediments have lower velocity (about $1700 \mathrm{~m} / \mathrm{s}$ ) than the sediments that lie between SP 550 and 750 (where the velocity is about $1850 \mathrm{~m} / \mathrm{s}$ ). This is probably due to a different level of sediment compaction.

Between SP 270 and 330, the velocity field shows a shallow area of low velocity compare to the upper and lower sediments (Figure 12.18b). This area lies just under a reflector with reversed polarity which we interpret as a bright spot that caps the gas within the underlying sediments (Figure 12.18a).

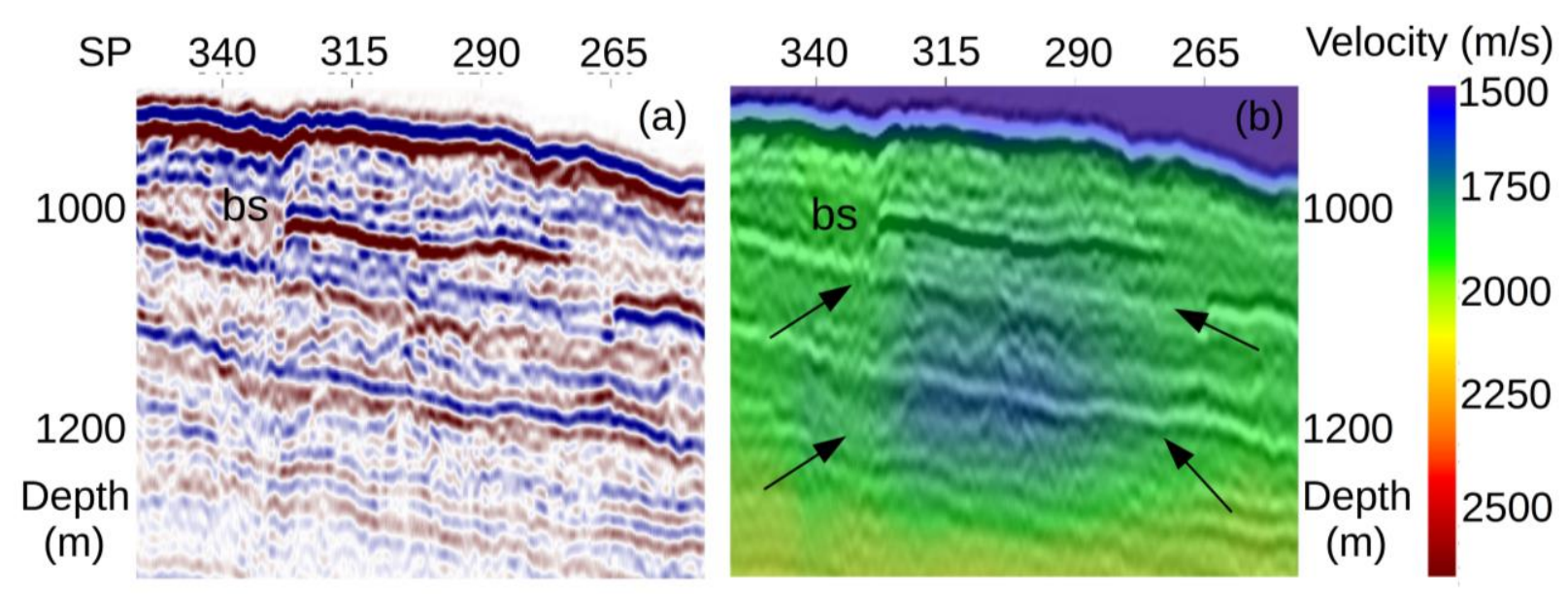

Figure 12.18: Portion of PSDM showing shallower bright spot (left); the same part of the section with the interval depth velocity superimposed (right). A low velocity zone below the bs testifies to the presence of gas within the sediments that are capped by the bs.

The depth image section shows the real geometry of the geological structures, particularly in areas of strong lateral velocity changes (Figure 12.19). Image distortions, such as pull-up or pull-down effects that affected the PSTM section, have been well resolved by the PSDM (Figure 12.20). This is a further validation of the velocity field obtained.

The PSDM section allows the possibility to directly calibrate the main geological units with well data. Unfortunately, the only borehole sited near the MS-29 line is the Merlo-001, which is located on a structural high of the Apulia Carbonate Platform, where the sedimentary succession is not complete. 


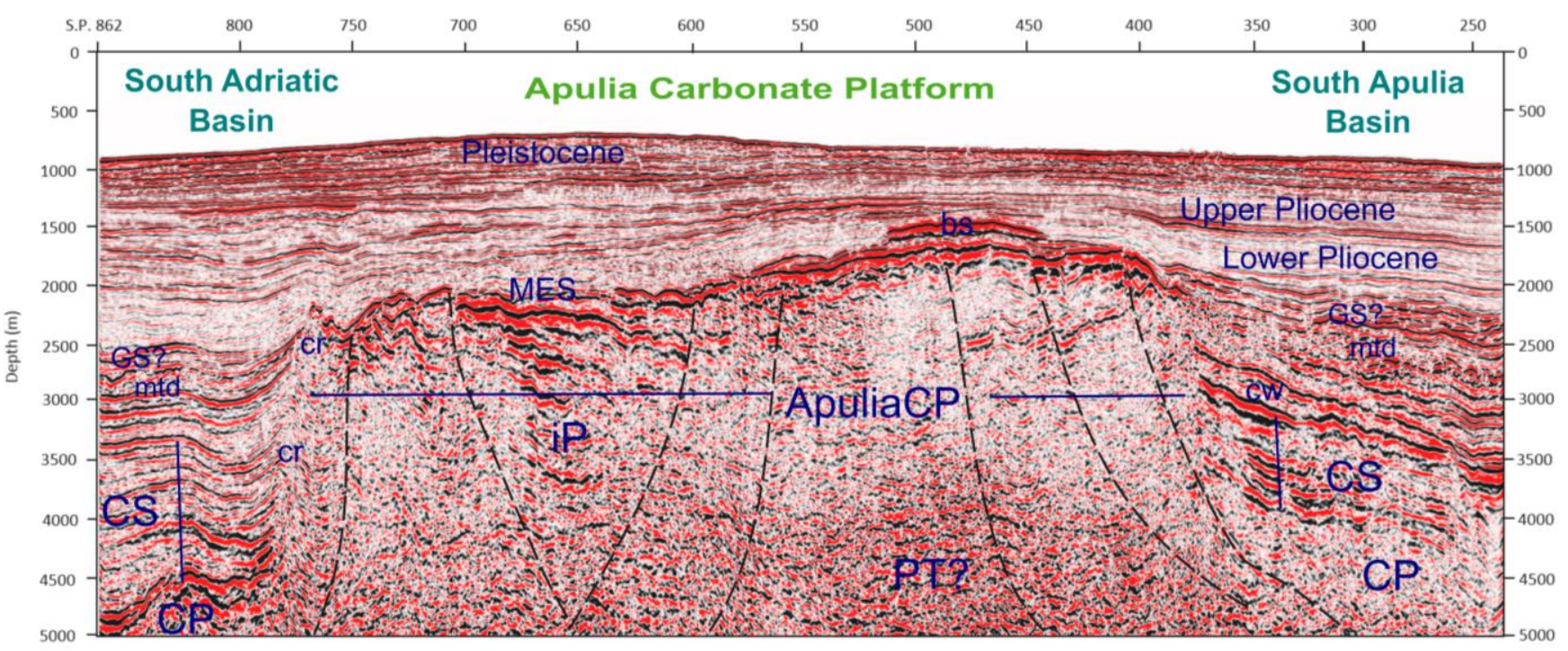

Figure 12.19: a portion of MS-29 PSDM section. Vertical exaggeration is $x 20$. The CP drowned in the Middle Jurassic, was successively covered by the pelagic CS. Coral reefs (cr) are interpreted at the northern edge of the CP. A stratified sequence ( $i P)$ is interpreted as deposition in an intraplatform/lagoonal environment. The high amplitude signal above the middle CP was previously interpreted by Del Ben et al. (2011) as a bright spot related to gas accumulation. The MES is evidenced by truncation of underlying reflectors. A GS sequence has been hypothesized in both the basins on the base of typical high amplitude reflectors. Mass transport deposit has been interpreted in both the basins, while a chaotic wedge could be related to reactivation of normal faults of the platform margin. 

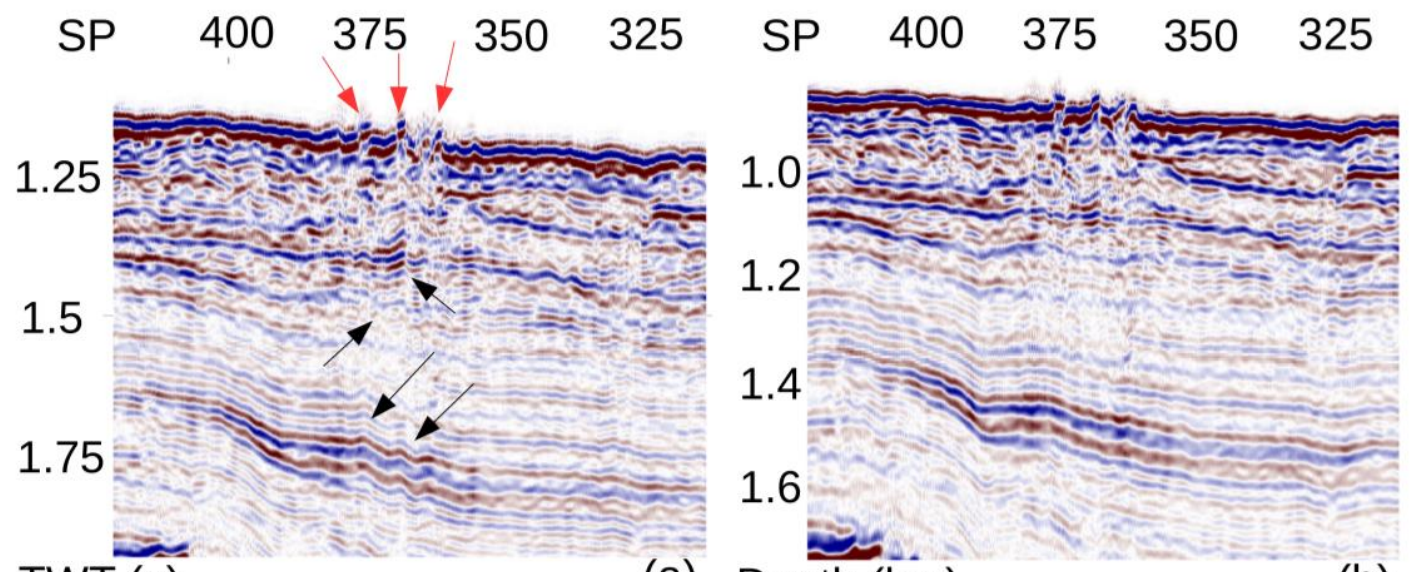

TWT (s)

(a) Depth $(\mathrm{km})$

(b)

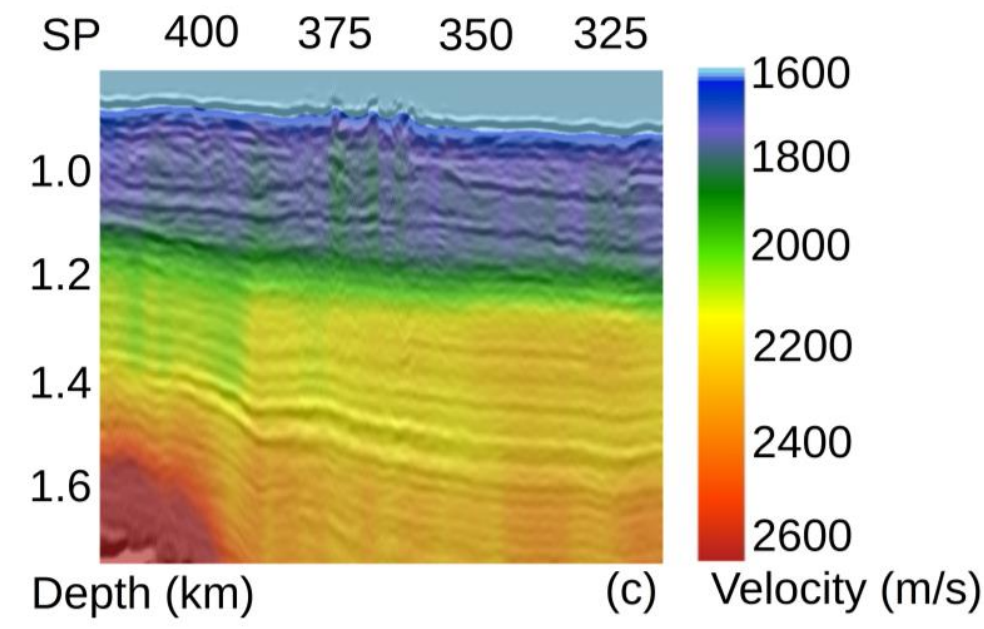

12.20 PSTM (a) showing a pull-up effect (black arrows) of the deeper reflectors by high velocity coral mounds (red arrows). (b) shows better imaging of the subsurface features obtained after PSDM with the velocity field displayed in (c).

\subsection{Seismic Interpretation}

In the central part of the reprocessed PSTM section, the Apulia carbonate platform is represented by a massive body, approximately $80 \mathrm{~km}$ wide, bounded by the South Adriatic Basin in the North and by the South Apulia Basin in the South (Figure 12.15b).

The MS-29 PSTM and PSDM (for the central part of the profile, SP 240-842, Figure 12.19) sections allowed the interpretation, from top to bottom, of several features:

- Gas accumulation: the presence of gas in the sedimentary sequence can be evidenced by high amplitude reflectors with negative polarity, known as bright spots. We observe bright spots in the shallowest strata (Neogene, particularly Plio-Quaternary), where acoustic impedances are more sensitive to the gas content (Figures 12.16, 12.18, 12.21). The presence of gas in the Adriatic Sea is known and has been exploited since the middle of the last century. The new processing better highlights these features, allowing us to distinguish genuine free gas manifestations from possible tuning effects related to pinch-out termination (Figure 12.19). 

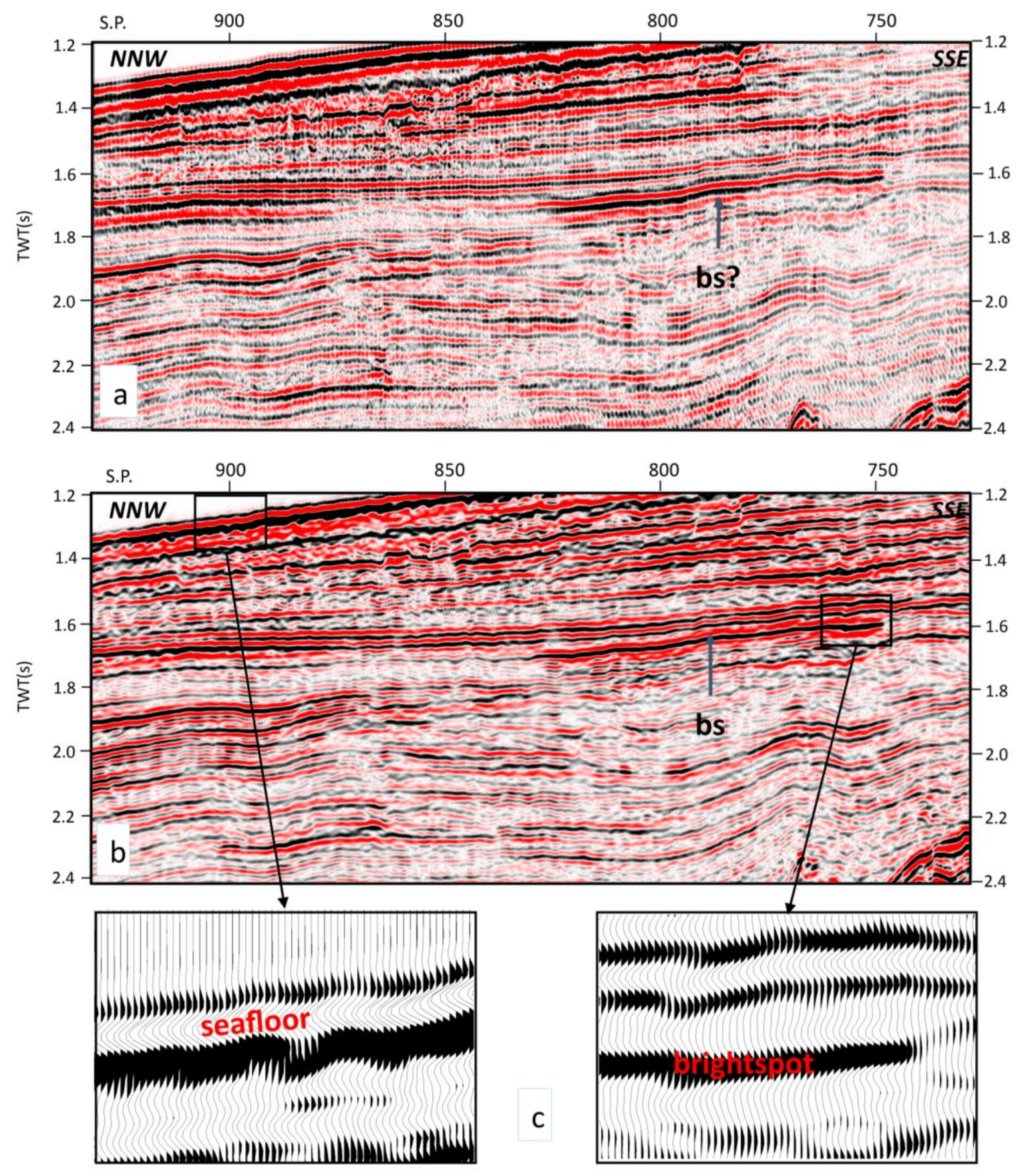

Figure 12.21: The high amplitude reflector (bs) enclosed in the yellow ellipse (a) shows reverse polarity (opposite to the seabed reflector) in (b), where it results to be more resolved and distinguishable from the overlaying reflector after reprocessing. In the vintage section (a) the polarity inversion is not clearly detectable due to lower resolution and tuning effect. 
- Diffuse gas: acoustically anomalous zones, where reflections appear strongly dimmed, very weak or absent (wipe-out zones) may point to the presence of diffuse gas within the sediments (Løseth et al., 2009). Gas chimneys, a seismic manifestation of focused gas migration through subvertical structures (faults or fractures in rocks) are often capped by high-amplitude reflections (bright spot), indicating gas accumulation at their upper termination (Figures 12.16 and 12.20). In the Adriatic Sea, they are typically fed by biogenic gas produced inside the Plio-Quaternary sequence (Casero, 2004; Cazzini et al., 2015).

- Messinian event: an erosional truncation of medium/high amplitude (MES) is a common marker in the Mediterranean Sea, related to the Messinian Salinity Crisis (Lofi, 2018.). Locally, it becomes a higher amplitude signal that is split into a seismic package of two or more high amplitude reflectors. We hypothesize the local presence of the Gessoso Solfifera Formation, which is often found in the Adriatic Sea, where it is calibrated by several boreholes and characterized by typical seismic markers along the profiles (Del Ben et al., 2018). Generally, below the Gessoso Solfifera Formation, the Adriatic boreholes cross the hemipelagic Serravallian-Tortonian Schlier Formation.

- Pelagic sequences: the two basinal domains in the northern and southern parts of MS-29 line are well described by high amplitude reflectors of the pre-Pliocene upper siliciclastic deposits covering the medium/high amplitude reflectors of the Jurassic/Paleogenepelagic carbonate sequence (CS) (Del Ben et al., 2015). A mass transport deposit imbued by fluid, characterized by a semitransparent chaotic seismic facies (Figures 12.17 and partly 12.19), broke away gliding along the slope, probably during the Neogene. Also, the triangular chaotic wedge (cw) confined by two high amplitude reflectors converging at SP 250 (Figure 12.19) is interpreted as a gravity sliding.

- Carbonate platform (CP): multiple attenuation and higher quality of imaging allow us to better distinguish the stratified layers of the pelagic sequence from the underlying or adjacent semiopaque seismic facies of the carbonate platform. In the central part of the MS-29 profile (SP 400750), this lithological unconformity, representing the Apulia carbonate platform's top, is at 2.0$2.4 \mathrm{~s}$ TWT (1700-2500 $\mathrm{m}$ depth). Some reflectors within the CP suggest some drowning facies (iP), likely related to local submersion events.

- Permo-Triassic clastic sequence (PT): despite the high energy absorption by the carbonate platform, the platform base shows the transition from the $\mathrm{CP}$ opaque seismic facies to the stratified sequence of the underlying PT. Thanks to the multiple removal, this last is evidenced along the reprocessed MS-29 profile at SP 100-220 and depth of 4.0-4.5 s TWT (Figure 12.15b) by a rough discontinuous stratification. This deep part of the profile cannot be reliably depth migrated, but we can estimate a Top PT depth of approximately 5 kilometres. 


\subsection{Morphological and Geodynamic Insights}

By integrating the reprocessed MS-29 line with other geological and geophysical data, we can make some observations related to the Apulia carbonate platform. The MS-29 profile crosses the $\mathrm{CP}$ in its "promontory" extension, between the CP outcropping in the Apulia region and in the Karaburun Peninsula, where the platform is thrusted and tilted below the Albanian Chain. The seismo-stratigraphy shows that the massive body of the $\mathrm{CP}$ is characterized by a range of internal seismic facies and structural patterns, partially due to (re-)activation of normal faults and related block-tilting (Figure 12.19). Inhomogeneities in seismic facies can be correlated to different shallow water depositional environments, with complex paleogeographic evolution.

The tectonic structures at the southern part of the MS-29 profile (Figures 12.15b and 12.17b) have been better resolved. The multiple removal has revealed a transpressional system that deforms the deep and the shallow sequences of the South Apulia Basin. The regional tectonics were interpreted by Argnani et al. (1993) as originating from Adria tilting toward the Calabrian Arc, to the West, and toward the Albanian chains, to the East. Del Ben (2009) related them to a recent inversion of Pliocene normal faults. The reprocessed MS-29 line shows several sub-vertical faults converging in depth. This suggests a transpressive deformation, also evidenced in the northern part of the CROP-M8 line (Figure 12.22). The inferred NE-SW direction of this transpressive system could be interpreted as an effect of the outermost migration of the Corfù Arc compared to the adjacent Albanian Chain. Furthermore, as we can see in Figure 12.23, the transpressive system intersects the isolated carbonate platform depicted by Del Ben et al. $(2010,2015)$ in the South Apulia Basin, where a cluster of several earthquakes is recorded (Castello et al., 2006).

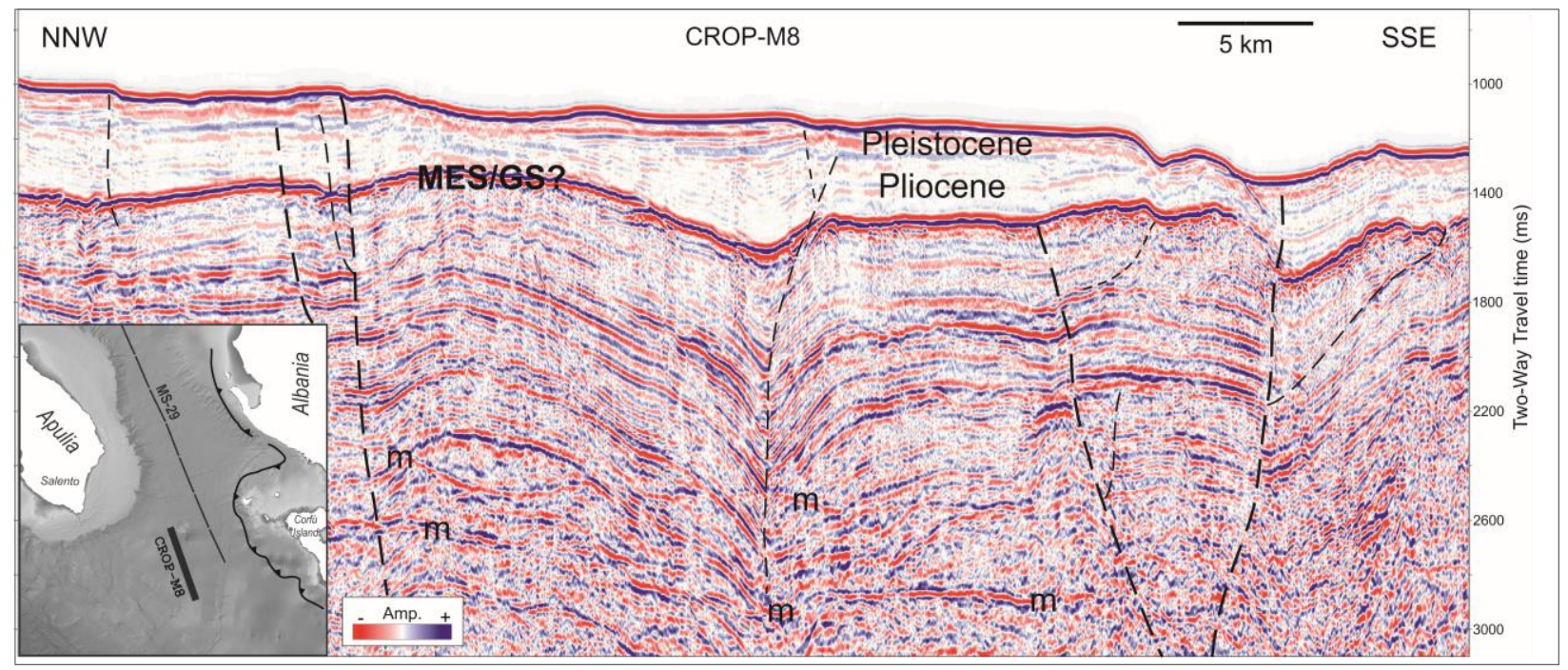

Figure 12.22: Portion of the CROP-M8 profile (modified from ViDEPI, 2009), approximately parallel to the MS-29 (see Figure 12.1 for locations). The deformation fabrics evident in MS-29 line (Figure 12.17) are also apparent on this line, in an external position of the Corfu sector of the Albanian Belt. The inverse faults and the folded Pleistocene layer confirm the compressive nature of deformation. An irregular, partially deformed sea bottom suggests that faults are currently active. " $m$ " denotes multiple. 


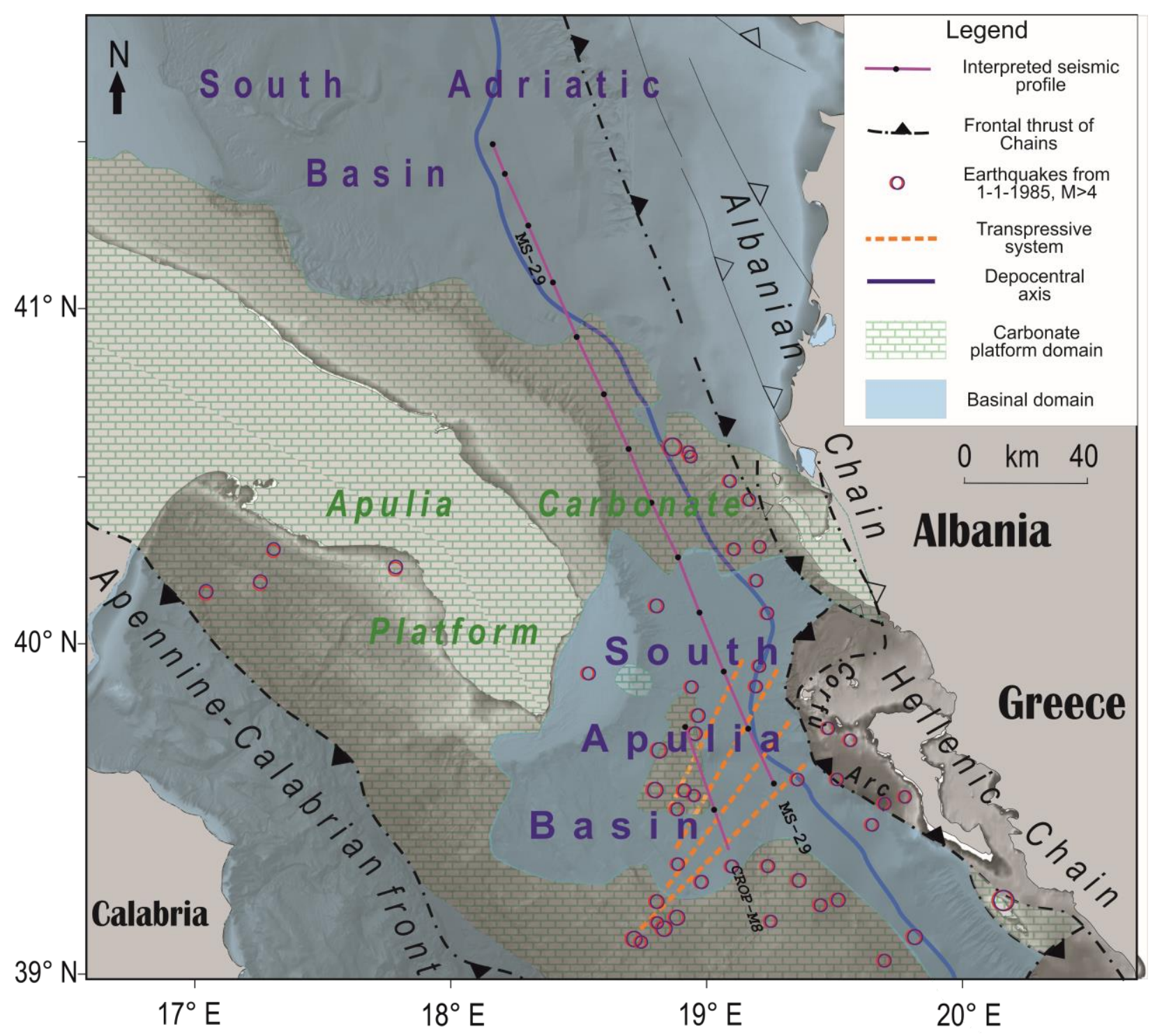

Figure 12.23: Geological scheme of the region, crossed by the reprocessed MS-29 line. The seismic line crosses the eastern extension of the Apulia carbonate platform, which reaches the Albanian onshore (margins by Del Ben et al., 2015) and, during and after the Mesozoic, separated the South Adriatic Basin from the South Apulia Basin. The transpressive system (red dashed lines) evidenced on the southern reprocessed MS-29 and in the CROP-M8 lines, seems to match the outermost migration of the Corfù Arc compared to the Albanian Chain and of the opposing Calabrian Arc. The system intercepts an isolated carbonate platform inside the South Apulia Basin, where an earthquakes cluster has been recorded.

The ACP, here tilted toward the Albanian Chain (Fantoni e Franciosi, 2008; Argnani, 2012), is crossed by the profile MS-29 (Figure 12.15), located not far west of the depocenter axis of the 
Otranto Channel (Figure 12.23). Figure 12.16 shows that in the deepest channel, the upper (Pleistocene?) sediments are not deposited and/or eroded. This suggests that the sea bottom currents, which connect the Adriatic and the Ionian seas, were particularly active in recent time, while the Pleistocene sequence was sourced by the erosion of the uplifting ACP and prograding on the continental platform with downlap termination (Del Ben et al., 2015) above the sub-parallel Pliocene layers. This also suggests a Pliocene continuous single depositional domain between the South Adriatic and South Apulia basins, without strong water currents. Otherwise, during the Messinian first sea level drop, the Apulia CP promontory was separating the basins, where deposition of gypsum was feasible (GS in Figure 12.16 and 12.19). Gypsum was affected by partial erosion during the further sea level drop (MES in both the basins in Figure 12.19). Consequently, we can argue that, during the Messinian, the Apulia CP promontory probably separated the connection between the Adriatic and the Ionian seas.

\section{CONCLUSIONS}

Vintage seismic data are of significant value for the scientific community, especially when reprocessed with up-to-date methodologies. In this chapter, we demonstrated that a specific processing flow and velocity modelling workflow can significantly improve the imaging of geological features within old data. In particular, the proposed time reprocessing flow enabled us to overcome aliasing problems related to low fold coverage that affected the performance of SRME and PSTM. To avoid spatial aliasing, we included two interpolation steps in the processing sequence, which increased the fold coverage for SRME and migration, respectively.

The application of both SRME and WEMA algorithms strongly attenuate the energy of multiple reflections, showing that this is also an optimal approach for treating vintage, low coverage seismic data.

The temporal resolution has been improved by broadening the frequency bandwidth and applying a designature procedure consisting of three main steps: de-ghosting, Q correction and surface consistent deconvolution.

A specific velocity modelling workflow was adopted, using the coherence inversion technique to build an optimal initial model and then using both the layer-based and the grid tomography to refine it. The final velocity model enables a reliable depth image of the MS-29 seismic line for the first time.

The reprocessing and depth imaging of the MS-29 seismic line lead to an easier and more reliable interpretation of the seismic horizons, seismic facies and seismic amplitude anomalies.

Our major new geological insights in the South Adriatic Sea can be summarized as follow:

- Gas chimneys and wipe-out zones testify to the presence of gas. This presence is consistent with some bright spots related to gas accumulation, which we interpret inside the PlioQuaternary sequence.

- The stratigraphic architecture of the Apulia CP is related to reactivation of normal faults and sea level changes triggering different depositional systems. Above the northern margin, a coral reef is interpreted, drowned below the Pliocene sequence.

- The base of the Carbonate Platform, underlying the pelagic Middle Jurassic-Neogene sequence of the South Apulia Basin, has been evidenced at a depth of $4 \mathrm{~s}$ TWT, approximately corresponding to $5 \mathrm{~km}$. 
- At the foot of the southern margin of the platform, a chaotic wedge is likely related to tectonic activity during Neogene time, probably associated with faults activity. Also, we identify a chaotic layer within both basins, that we attribute to mass transport deposits.

- An active transpressive system has been recognized which cuts the Albanian-Hellenic Chain, allowing the Corfù Arc to migrate further west then the Albanian Chain. Earthquakes recorded in the same region could be related to the intersection of the fault system with an isolated carbonate platform present inside the South Apulia Basin.

- Above a regular deposition of Pliocene layers, which covers in continuity the South Adriatic Basin, the Apulia CP and the South Apulia Basin, the Pleistocene sequence is thicker at the top of the carbonate platform and is thinning. This is due to no deposition or erosion, above both basins, where the seismic profile is slightly west of the axial depocenter. This suggests that the sea bottom currents connecting the Adriatic and the Ionian seas were particularly efficient only since the Pleistocene. During the Messinian sea level drop, this connection was probably barred by the Apulia CP promontory.

\section{Acknowledgements}

The authors acknowledge academic grants from Emerson Paradigm for Echos and Geodepth software and HIS Markit for Kingdom Suite software. The authors would like to thank the scientific and technical crew of the R/V Marsili and of the OGS's staff for the enormous and inestimable work carried out over several years of systematic Mediterranean exploration. Without the efforts carried out, in the past, to save the original data, this work would not have been possible.

\section{Chapter References}

Abma, R., Kabir, N., Matson, K. H., Michell, S., Shaw, S. A., McLain, B., 2005. Comparisons of adaptive subtraction methods for multiple attenuation: The Leading Edge, 24, 277-280.

Argnani, A., Favalli, P., Frugoni, F., Gasperini, M., Ligi, M., Marani, M., Mattietti, G., Mele, G., 1993. Foreland deformational pattern in the Southern Adriatic Sea. Annals of Geophysics, 36(2).

Argnani, A., Favali, P., Frugoni, F., Gasperini, M., Ligi, M., Marani, M., Mele, G., 1996. Tettonica dell'Adriatico meridionale. Mem. Soc. Geol. It.

Argnani, A., 2012. Plate motion and the evolution of Alpine Corsica and Northern Apennines. Tectonophysics, 579, 207-219.

Ballauri, A., Bega, Z., Meehan, P., Gambini, R., Klammer, W., 2002. Exploring in structurally complex thrust belt: Southwest Albania Case. In AAPG Hedberg Conference.

Borgomano, J., Philip, J., 1987. The rudist carbonate build-ups and the gravitary carbonates of the Gargano-Apulian margin (southern Italy, Upper Senonian). Mem. Soc. Geol. It, 40, 125-132.

Bosellini, A., Neri, C., Luciani, V., 1993. Guida al cerbonati Cretaceo-Eocenici di scarpata e bacino del Gargano (Italia meridionale). Annali/Univ. di Ferrara, NS, Sez.: Scienze della Terra.

Bosellini, F. R., Russo, A., Vescogni, A., 2001. Messinian reef-building assemblages of the Salento Peninsula (southern Italy): palaeobathymetric and palaeoclimatic significance. Palaeogeography, Palaeoclimatology, Palaeoecology, 175(1-4), 7-26. 
Casero, P., 2004. Structural setting of petroleum exploration plays in Italy. Special Volume of the Italian Geological Society for the IGC 32 Florence-2004: 189-199.

Castello, B., Selvaggi, G., Chiarabba, C., Amato, A., 2006. CSI Catalogo della sismicità italiana 1981-2002, versione 1.1. INGV-CNT, Roma, http://www.ingv.it/CSI/.

Cazzini, F., Zotto, O.D, Fantoni, R., Ghielmi, M., Ronchi, P., Scotti, P., 2015. Oil and gas in the Adriatic foreland, Italy. Journal of Petroleum Geology, 38(3), 255- 279.

Claerbout, J. F., 1992. Earth Soundings Analysis: Processing Versus Inversion. Blackwell Scientific Publications.

Cosentino, D., Gliozzi, E., 1988. Considerazioni sulle velocità di sollevamento di depositi eutirreniani dell'Italia meridionale e della Sicilia. Memorie della Società Geologica Italiana, 41, 653-665.

Costa, E., Camerlenghi, A., Polonia, A., Cooper, C., Fabretti, P., Mosconi, A., Murelli, P., Romanelli, M., Sormani, L., Wardell, N., 2004. Modelling deformation and salt tectonic in the Eastern Mediterranean Ridge accretionary wedge. Geological Society of America Bulletin, v. 116, pp. 880-894.

D'Argenio, B., Horvath, F., Channel, J.E.T., 1980. Paleotectonic evolution of Adria, the Africa promontory. Mem. BRGM, 115, Coll. C5: geologie des chaines alpines issues de la Tethys, $26^{\circ}$ CGI, 331-351.

Dal Cin, M., Del Ben, A., Mocnik, A., Accaino, F., Geletti, R., Wardell, N., Zgur, F., Camerlenghi A., 2016. Seismic imaging of the Late Miocene (Messinian) evaporites from Western Mediterranean back-arc basins. Petroleum Geoscience. Published online first.

Del Ben, A., 2009. Earthquakes and shallow structures in South Adria: evidence of recent inversion tectonics. In: Recent Progress on Earthquake Geology, pp. 147-163. Nova Science Publishers.

Del Ben, A., Geletti, R., Mocnik, A., 2010. Relation between recent tectonics and inherited Mesozoicstructures of the central-southern Adria plate. Bollettino di Geofisica Teorica ed Applicata, 51 (2-3), 99-115.

Del Ben, A., Mocnik, A., Volpi, V., Karvelis, P., 2015. Old domains in the South Adria plate and their relationship with the West Hellenic front. Journal of Geodynamics, 89, 15-28.

Del Ben A., Geletti R., Mocnik, A., Castagner, R., 2018. - 13. A, B, C- Central Adriatic Basin. In. J. Lofi, Ed., Seismic atlas of the Messinian salinity crisis markers in the Mediterranean sea. Volume 2 - Mem. Soc. geol. Fr., n.s, 2018, t 181, and Commission for the Geological Map of the World, p. 45-47.

Del Ben A., Geletti R., Bertone N., Brancatelli G., Forlin E., Mocnik A., 2020. New seismic data on the carbonate platform structures in the Otranto Channel (South Adriatic Sea). Submitted to the 82th EAGE Conference and Exhibition 2020, Jun 2020.

Dix, C. H., 1955. Seismic velocities from surface measurements: Geophysics, 20 , 68-86.

Dragoset, B., 2005. A historical reflection on reflections. The Leading Edge, 24 (s1):s46.

Dragoset, W. H., 1990. Air-gun array specs: A tutorial. Leading Edge, 9, 24-32, doi:10.1190/1.1439671.

Fantoni, R., Franciosi, R., 2008. Geological sections crossing Po Plain and Adriatic foreland. Rend. online Soc. Geol. It., 3, 365-366.

Finetti, I., Del Ben, A., 1986. Geophysical study of the Tyrrhenian opening. BGTA, 28 (110), 75- 
155.

Finetti, I., Morelli, C., 1972. Wide scale digital seismic exploration of the Mediterranean Sea. Bollettino di Geofisica Teorica e Applicata, 14 (56), 291-342.

Finetti, I., Morelli, C., 1973. Geophysical exploration of the Mediterranean Sea. Bollettino di Geofisica Teorica e Applicata, 15 (60), 263-340.

Finetti, I., Morelli, C., Zarudzki, E., 1970. Reflection seismic study of the Tyrrhenian Sea. Bollettino di Geofisica Teorica e Applicata 12 (48), 311-346

Finetti, I., Bricchi, G., Del Ben, A., Pipan, M., Xuan, Z., 1987. Geophysical study of the Adria plate. Mem. Soc. Geol. It, 40, 335-344.

Finetti, I. R., Del Ben, A., Forlin, E., Prizzon, A., 2005a. Review of the Main Results of the Pioneering MS Seismic Exploration Programme in the Deep Water of the Mediterranean Sea. CROP Project: deep seismic exploration of the central Mediterranean and Italy, 1-30. Atlases in geoscience, 1, Elsevier.

Finetti, I. R., Lentini, F., Carbone, S., Del Ben, A., Di Stefano, A., Forlin, E., Guarnieri P., Pipan M., Prizzon, A., 2005b. Geological outline of Sicily and lithospheric tectono dynamics of its Tyrrhenian margin from new CROP seismic data. CROP Project: deep seismic exploration of the central Mediterranean and Italy, 319-375. Atlases in geoscience, 1, Elsevier.

Fomel, S., 2002. Applications of plane-wave destruction filters. Geophysics, 67, 6.

Geletti, R., Zgur, F., Del Ben, A., Buriola, F., Fais, S., Fedi, M., Forte, E., Mocnik, A., Paoletti, V., Pipan, M., 2014. The Messinian Salinity Crisis: new seismic evidence in the West-Sardinian Margin and Eastern Sardo-Provençal basin (West Mediterranean Sea). Marine Geology, 351, 7690.

Górszczyk, A., Cyz, M., Malinowski, M., 2015. Improving depth imaging of legacy seismic data using curvelet-based gather conditioning: A case study from Central Poland. Journal of Applied Geophysics, 117, 73-80.

Hale, D., 1981, An inverse-Q filter: Stanford Exploration Project Report 26.

Hargreaves, N. D., Calvert, A. J., 1991, Inverse Q filtering by Fourier transform. Geophysics, 56, 519-527.

Hestenes, M. R., Stiefel, E., 1952. Methods of Conjugate Gradients for Solving Linear Systems. Journal of Research of the National Bureau of Standards, 49, 409-435.

Jones, I. F., Sugrue, M., Hardy, P., 2007. Hybrid Gridded Tomography. First Break 25 (1106).

Jones, I. F., 2010. An Introduction to Velocity Model Building. EAGE publications, ISBN 97890-73781-84-9, 296 pages.

Jones, I. F., 2018. Velocities, Imaging and Waveform Inversion. EAGE publications, ISBN 97894-6282-253-5.

Kjartansson, E., 1979. Constant-Q wave propagation and attenuation. Journal of Geophysical Research 84, 4737-4748.

Landa, E., Kosloff, D., Keydar, S., Koren, Z., Reshef, M., 1988. Method for determination of velocity and depth from seismic reflection data. Geophysical Prospecting, 36(3), 223-243.

Levin, S. A., 1989. Surface-consistent deconvolution. Geophysics, 54, 1123-1133.

Lofi, J., 2018. Seismic atlas of the Messinian salinity crisis markers in the Mediterranean sea. Volume 2 - Mem. Soc. geol. Fr., n.s, 2018, t 181, and Commission for the Geological Map of the World, 72p., doi 10.10682/2018MESSINV2. 
Løseth, H., Gading, M., Wensaas, L., 2009. Hydrocarbon leakage interpreted on seismic data. Mar. Pet. Geol., 26, 1304- 1319.

Lumley, D., Claerbout, J., Bevc, D., 1994, Anti-aliased Kirchhoff 3-D migration: 64th Ann. Internat. Mtg.,Soc. Expl. Geophys., Expanded Abstracts, 1282-1285.

Luo, Z., Brittan, J., Fan, D., Mecham, B., Farmer, P., Martin, G., 2014. Imaging complexity in the earth - Case studies with optimized ray tomography. The Leading Edge, 33, no. 9, 1016-1022.

Mattavelli, L., Novelli, L., Anelli, L., 1991. Occurrence of hydrocarbons in the Adriatic basin. Spec. Publ. EAPG, 1, 369-380.

Mocnik, A., 2008. Metodologie geofisiche integrate per la correlazione tra strutture superficiali e profonde nel Canale di Otranto. MD Thesis, University of Trieste.

Munteanu I., Diviacco P., Sauli C., Dinu C., Burcă M., Panin N., and Brancatelli G., 2018. New Insights into the Black Sea Basin in the Light of the Reprocessing of Vintage Regional Seismic Data. In: Finkl C., Makowski C. (eds) Diversity in Coastal Marine Sciences. Coastal Research Library, vol 23. Springer, Cham.

Nicolai, C., Gambini, R., 2007. Structural architecture of the Adria platform-and-basin system. Bollettino della Società Geologica Italiana, 7, 21-37.

Nicholls, H., Penn, L., Marszalek, A., Esestime, P., Rodriguez, K., Benson, C., Cvetkovic, M., 2015. The role of legacy seismic in exploring new offshore hydrocarbon provinces - or can you "teach" old data new tricks (technologies)?. SEG Technical Program Expanded Abstracts: 19171921.

Oppenheim, A.V., Schafer, R.W. 1975. Digital Signal Processing, Prentice Hall, Englewood Cliffs, N.J.

Prakash, A., Singh, V., Saxena, U. C., Sen, G., 1998. Impact of Surface Consistent Deconvolution on Wavelet Stability and Seismic Attributes: A Case Study. In 60th EAGE Conference and Exhibition (pp. cp-110). European Association of Geoscientists \& Engineers.

Ricchetti, G., Ciaranfi, N., Luperto Sinni, E., Mongelli, F., Pieri, P., 1988. Geodinamica ed evoluzione sedimentaria e tettonica dell'avampaese apulo. Mem. Soc. Geol. It, 41(1), 57-82.

Robinson, E. A., Treitel, S. 1980. Geophysical Signal Analysis, Prentice Hall, Englewood Cliffs, N.J.

Romeo R., Geletti R., Caburlotto, A., Zgur, F., Codiglia, R., Cova, A., Facchin, L., Ramella, R., 2011. Deep-water coral communities in the Otranto Channel revealed by acoustic methods and gravity cores during a 2011 R/V OGS Explora survey. In: Geoitalia 2011, VIII Forum Italiano di Scienze della Terra. Poster and abstract, 10.1474/Epitome.04.0954. ISSN 1972-1552.

Stampfli, G. M., 2005. Plate tectonics of the Apulia-Adria microcontinents. CROP Project: deep seismic exploration of the central Mediterranean and Italy, 747-764. Atlases in geoscience, 1, Elsevier.

Sopher, D., Juhlin, C., 2013. Processing and interpretation of vintage 2D marine seismic data from the outer Hanö Bay area, Baltic Sea. Journal of Applied Geophysics, 95, 1-15.

Tinti, S., Maramai, A., Favali, P., 1995. The Gargano promontory: an important Italian seismogenic-tsunamigenic area. Marine Geology, 122(3), 227-241.

Treitel, S., Lines, L., 2001. Past, Present, and Future of Geophysical Inversion-A New Millennium Analysis. Geophysics 66 (1): 21. 
Tribolet, J. M., Quatieri, T. F., 1979. Computation of the Complex Cepstrum. Programs for Digital Signal Processing, IEEE Press, pp. 7.1-1 to 7.1-11.

Ulrych, T., J., Velis, D., R., Sacchi, M., D., 1995. Wavelet estimation revisited. The Leading Edge 14: 1139-1143.

Van der Baan, M., 2012. Bandwidth enhancement: Inverse Q filtering or time-varying Wiener deconvolution?. Geophysics, 77, no. 4, V133-V142

Vai, G. B., 1994. Crustal evolution and basement elements in the Italian area: palaeogeography and characterization. Bollettino di Geofisica Teorica ed Applicata, 36(141-44), 411-434.

Verschuur, D. J., Berkhout, A. J., Wapenaar, C. P. A., 1992. Adaptive surface-related multiple elimination, Geophysics, 57, 1167-1177.

Verschuur, D. J., 2013. Seismic Multiple Removal Techniques: Past, present and future. Revised Edition. EAGE publications. ISBN:978-90-73834-56-9.

ViDEPI - Project 2009. Visibility of petroleum exploration data in Italy. https://www.videpi.com. Wang, Y., 2004. Q Analysis on Reflection Seismic Data. Geophysical Research Letters 31.

Wang, Y., 2008. Seismic Inverse Q Filtering. Oxford, Blackwell Publishing.

Weglein, A.B., Stolt, R.H., 1999. Migration Inversion Revisited. The Leading Edge 18 (8): 950, 975.

Wiggins, J. W., 1988. Attenuation of complex water-bottom multiples by wave-equation-based prediction and subtraction. Geophysics, 53, 1527-1539.

Yilmaz, O., 2001. Seismic data processing. Investigation in geophysics. ISBN 978-1-56080-0941.

Yilmaz, O., Baysal, E., 2015. An Effective Ghost Removal Method for Marine Broadband Seismic Data Processing. Conference Proceedings, 77th EAGE Conference and Exhibition 2015, Jun 2015, Volume 2015, p.1 - 5 .

Zappaterra, E., 1990. Carbonate paleogeographic sequences of the Periadriatic region. Bollettino della Società Geologica Italiana, 109(1), 5-20.

Zhou, Z., Cvetkovic, M., Xu, B., Fontana, P., 2012. Analysis of a Broadband Processing Technology Applicable to Conventional Streamer Data. First Break, 30, 77-82.

Zhou. J., Chia, P., Masoomzadeh, H., Ma, X., Goh, T., 2015. Pre-stack deghosting: Bringing out the seismic bandwidth in legacy marine data. ASEG ExtendedAbstracts, 2015:1, 1-4. 